\title{
El porvenir de la descentralización ante el proceso planificador. Esquema para un planteamiento actual del tema ${ }^{(*)}$
}

\author{
$35.072 .1(46)$
}

\author{
por \\ GASPAR ARIÑO ORTIZ \\ Profesor Numerario de la Escuela Nacional de Administración Pública. \\ Antigua Universidad de Alcaĺ de Henares.
}

SUMARIO: I. ¿SOMBRIAS PERSPECTIVAS DE FUTURO PARA LA DESCEN. TRALIZACION? - II. EL TEMA CENTRAL: LA PARTICIPACION DE LAS CORPORACIONES LOCALES EN EL PODER. CONCEPCION TRADICIONAL. III. LA NUEVA VISION DEL TEMA: 1. Comprensión unitaria de la Admi. Nistración pública, 2. La «Nacionalización» dE LAS TAREas. 3. EL IMPaCto de la programación y el proceso de decisión. La partición funcional de compe. tencia: A) $A$ nivel de la decisión. B) A nivel de la ejecución. 4. Necesaria flexibilidad del Ordenamiento. 5. La renovada potenciación de los entes locales como «INSTANCias》 de la Administración general del pais.-IV. UN EJEMPLO DE LO QUE NO HAY QUE HACER: EL TURISMO.-V. BREVE MIRADA AL TEMA REGIONAL.-VI. DESCENTRALIZACION, REGIONALIZACION, PARTICIPACION.-VII. CONCL.USION.

\section{I. ¿SOMBRIAS PERSPECTIVAS DE FUTURO PARA LA DESCENTRALIZACION?}

El tema de la descentralización ha estado muy presente en la realidad española de los últimos meses. Ante la perspectiva

${ }^{*}$ ) Se escribe este trabajo sobre el tema de la autonomia local desde una perspectiva muy concreta: la perspectiva planificadora y programadora del Estado moderno. No desconozco el riesgo de unilateralidad y necesaria parcialidad que tal enfoque supone. Pero entiendo que es éste-el de la integración de los entes locales en el proceso planificador-uno de los problemas centrales de nuestra reforma en marcha del Régimen local. Si no se aborda correctamente, hará de estas viejas unidades, cada vez más, entes decadentes, raquíticos y puramente 
de reforma del Régimen local, se han levantado desde todos los sectores voces de alabanzas y exaltación del sistema: ha habido afirmaciones ministeriales, declaraciones de expertos y nostálgicas reivindicaciones provincianas (1).

Ahora bien, dejando a un lado ingenuas utopías (2), y a la vista de la realidad que se nos avecina, pienso que tantos buenos propósitos no son fácilmente realizables. Más bien al contrario: las modernas técnicas de acción administrativa en el campo económico y social, parece empujan hacia la centralización (3).

folklóricos, sin una inserción activa y operativa en el orden jurídico-político unitario que es el Estado. Y ello, no obstante las declaraciones legales. También debo decir que este trabajo mira hacia el futuro, como se desprende del título. En él se dan por supuestas unas bases tanto tecnológicas como políticas y sociológicas de las que desde luego estamos muy lejos en este país. De ahí que, en algúr momento -pido perdón por ello-, el lector pueda tener la impresión de que le están contando una novela de ciencia-ficción. Bien sé que este tema del Régimen local, más que ningún otro, se encuentra vinculado al contexto socio-político, y que por tanto serán siempre inadecuadas unas soluciones nominalistas desconectadas de aquél. Si, a pesar de todo, lo he escrito, es porque creo firmemente que el esquema que aquí se esboza constituye un camino adecuado para devolver a los entes. locales, y con ello a los ciudadanos, el papel de protagonistas (no sólo espectadores, aunque lo sean de primera fila) en la adopción de las decisiones políticas que les conciernen. $Y$ porque deseo que esta necesaria apertura y este proceso de revitalización política, que está en la base del sistema, se inicie cuanto antes.

(1) El tema venía siendo objeto de estudios previos tanto en el Instituto de Estudios de Administración Local como en el Ministerio de la Gobernación, y está en la calle desde principios de este año; a raíz del discurso del Ministro de la Gobernación en Barcelona, en febrero pasado, la prensa se ha ocupado ampliamente de él abogando por fórmulas descentralizadoras «como defensa del humanismo» (Nuevo Diario, 22.X-69), «como politica global» (Nuevo Diario, 10-II-70), «como instrumento de desarrollo económico» (La Vanguardia, 11-II-70), «como medio de actualizar la participación ciudadana» ( $A B C, 19-1 \mathrm{I}-70$ ), «como medio de participación del ciudadano en la planificación» (La Vanguardia, 3-III-70), etcétera. La descentralización es un auténtico «mito» que goza también hoy, como en épocas pasadas, de buena prensa. La doctrina científica no es menos generosa en prodigarle alabanzas a la descentralización como «factor decisivo para la formación de una conciencia democrática y de un sentido cívico efectivo». (Marrín. Retortillo, S., «Planificación y Administración local», en Crónica del IV Congreso Hispano-Luso-Americano-Filipino de Municipios, Barcelona, octubre 1967, tomo II, páginas 39 y sigs.). Destacando estas virtualidades democráticas de los entes locales, vid. por todos Martín Mateo, R., El horizonte de la descentralización, Instituto de Estudios de Administración Local, 1970.

(2) Martín-Retortillo, S., ha señalado cuán frecuentes han sido en este campo del Régimen local las marchas «hacia el reino de la utopia», hacia «unas esperanzas que jamás habrían de realizarse». («Planificación...», cit., pág. 54).

(3) No digo que no sean deseables, sino todo lo contrario: justamente porque lo son, resulta muy importante acertar con el camino para conseguirlo; y este camino no es nada fácil, porque las modernas técnicas de previsión y gestión admi- 


\section{André Delion ha puesto de manifiesto cómo hoy más que nun-} ca, cuando la Administración lleva a cabo una intervención sistemática y generalizada en la vida social, se impone «la unidad de acción» en todos sus niveles (centrales, regionales y locales), y postula para ello «la asociación permanente de las élites (ad-

nistrativa empujan en sentido contrario. Es conocida la polémica mantenida entre nosotros sobre este punto por Albi y Sebastián Martín.Rerortillo. Albi afirmó en 1966 (La crisis del municipalismo, pág. 329) que «la planificación es consus. tancial con la noción centralizadora, y constituye el contrapunto de la variedad, de la diversidad de gestión, en la que se basa, por principio, toda la concepción de lo municipal». Por otra parte-dice-《la planificación es inevitable; sin ella no puede desarrollarse la sociedad actual». Por ello se hace preciso buscar unas fórmulas de colaboración $y$ adaptación a las nuevas realidades, pero se trata-con. cluye- «de una dificil fórmula de acomodación que hasta ahora parece inasequible» (página 332). Frente a esta postura, Martí-Retortillo ha mantenido que no sólo puede hablarse de una compatibilidad entre planificación y entes locales, sino que incluso puede reconocerse «el potenciamiento directo que sobre la base de esa relación puede alcanzar a las Administraciónnes locales», si bien ello exige un renovado y más correcto planteamiento de éstas (ob. cit., págs. 46 y sigs., y en general a lo largo de todo el trabajo). Sin ánimo de terciar en la polémica debe decirse que es evidente el riesgo centralizador de la programación. Garrido FAlla, F., hablaba hace poco de una «tendencia inevitable hacia la centralización», que-decía-es preciso compensar (conferencia pronunciada en la Cámara Oficial de Comercio, Industria y Navegación de Bilbao el 20 de marzo de 1970). Y Giannini recordaba recientemente cómo la adopción de las técnicas de progra. mación abocaron inicialmente (hoy asistimos a un proceso lento de corrección de la tendencia) a un proceso de centralización, pues «se estimó en un primer mo. mento que los planes (y programas) no podrían ser sino decisiones de los órganos centrales» (en La, región como unidad de acción administrativa, C y D, Escuela Na. cional de Administración Pública, 1970, pág. 32). Ahora bien, ello no es ni mucho menos irreversible. Pienso que, en sí mismas, las técnicas de programación pueden servir a las finalidades centralizadoras o descentralizadoras según el animus de quien las utilice. Este trabajo es un intento, modesto, de abocar a una fórmula de descentralización. Para ello, como señala Martín-Retortillo, se hace necesario, como fase previa, racionalizar y planificar «la realidad misma de las propias Entidades municipales» (pág. 59) superando «los contrasentidos originarios del municipalismo tradicional» (Albi, cit. por Retortillo, pág. 61) y avanzando hacia unidades político-administrativas de mayores dimensiones, en las que sean viables los principios representativos y de participación, que son los grandes valores del Règimen local y los que con unas $u$ otras fórmulas interesa salvaguardar en un Estado progresivamente despersonalizado. Esta necesaria racionalización del Régi. men local ha sido unánimemente propugnada por la doctrina española que se ha ocupado del tema y concreciones de ella son la «provincialización del Régimen local» (García de Enterría), la «comarcalización» (Martín Mateo), las distintas versiones de ordenación del territorio y fórmulas de «desarrollo económico regional» (vid., por ejemplo, Ortiz Díaz, J., «El desarrollo económico regional, la Administración de misión y las Diputaciones provinciales», en Revista de Admi nistración Pública, núm. 50, 1966, págs. 9 a 26), etc. 
ministrativas y políticas) locales a la acción estatal» (4). EP instrumento de esa «unidad de acción» es, sin duda, la planificación, y ésta-se dice-no favorece la descentralización, sino todo lo contrario (5); en los sectores económicos y sociales, que son hoy la parte más importante de la acción administrativa, «la descentralización territorial-ha escrito CADOUX - resulta cada vez menos practicable», primero, porque se requieren circunscripciones sensiblemente más amplias que las tradicionales (y éstas no se improvisan), y segundo, porque resulta difícilmente articulable en los entes locales actuales un «poder de decisión efectivo, competente y autónomo», en la gran mayoría de los sectores (6).

Como resultado de un largo proceso de empobrecimiento y languidecimiento de la Vida local, es un hecho fácilmente comprobable que hoy autoridades y políticos desconfían-con razón-de los entes locales, no obstante sus platónicas declaraciones de amor.

En el fondo, la gran tentación del Estado de nuestros días es la de asociar a sus propias tareas a las colectividades locales, absorbiendo también en su propio beneficio los exiguos fondos. de éstas, o bien la de confiarles un mero papel de «consulta» o de «gestión» en sentido estricto (esto es, pura ejecución), pero privándoles en cualquier caso de un real poder de decisión sobre los llamados «asuntos locales», que serán constante y directa-

(4) André G. Delion, «Réforme administrative: déconcentration et unité d'action», en Droit Administratif, núm. 1, 1963, págs. 4 a 15.

(5) Cadoux, Ch., «L'avenir de la décentralisation territoriale», Droit Administratif, núm. 1, 1963, págs. 268 a 272 . Los métodos de planificación nacional y regional traen como consecuencia casi inevitable la muerte a la autonomía de los entes locales, «quedando la realidad del poder de decisión siempre en manos del poder central»; y ello porque-según este autor-la planificación impone en último término un centro único de decisión y una caja única financiera (centralización de los fondos). Veremos más adelante cómo esta determinación de causa y efecto n. es tan inexorable como cree Cadoux.

(6) Factores económicos y sociales-dice-imponen una presencia continua del poder central, tanto por razones de orden financiero como de orden técnico y tecnológico; y el «técnico-no se olvide-es por temperamento centralizador, pues piensa que la eficacia de su acción depende de directrices precisas y del cumplimiento estricto de los programas cuidadosamente preparados por él». (Vid. $\mathrm{C}_{\mathrm{A}}$ Doux, Ch., «L'avenir de la décentralisation territoriale», Droit Administratif, número 1, 1963, págs. 268-272. 
mente tratados-desde arriba-en función del conjunto nacional (7).

Estas afirmaciones podrán gustar o no, pero es para mí evidente que se ajustan a la realidad de todos los países. Será necesaria una decidida voluntad de descentralizar y un gran acierto en la elección del camino y de los medios para compensar la tendencia biológica del Estado moderno hacia la concentración y tecnificación del poder (8).

Este trabajo está dedicado a poner de manifiesto la necesidad de un nuevo approach al tema y a apuntar las posibles líneas de ese nuevo camino de la descentralización.

Antes, sin embargo, convendrá recordar-brevísimamenteel esquema clásico de la relación Estado-Corporaciones locales.

\section{EL TEMA CENTRAL: LA PARTICIPACION DE LAS CORPO. RACIONES LOCALES EN EL PODER. CONCEPCION TRADICIONAL}

Las coordenadas tipificadoras de un Régimen local, sus dos temas esenciales, medulares, que lo configuran, son: 1) la elección de sus autoridades y el principio de representación en él imperante; y 2) el tema de la competencia, el tema de sus misiones y finalidades, de las tareas que competen a las Corporaciones locales. Uno y otro no son sino aspectos de un tema más general: el tema de su participación en el poder.

Es sobradamente conocida la explicación clásica, y ya hoy un tanto estereotipada, que del Régimen local español se ha hecho en una evolución histórica que arranca de la Revolución y que llega hasta nuestra actual Ley de Régimen local (9). Este planteamiento se basa esencialmente en los siguientes puntos:

(7) Este es el «negro horizonte» que pinta, por ejemplo, Cadoux, Ch., «L'avenir...», cit., pág. 272. Y algo de esto denunció entre nosotros García de ENTERría en relación con los «Planes provinciales». (Vid. lo que se dice infra, en nota).

(8) Es significativo en este sentido, como señala DebBasch, el contraste entre las firmes y sinceras declaraciones de descentralización que han hecho los hom. bres de la V República francesa, y la timidez y grandes cautelas con que ésta se está operando. (Vid. Debbasch, Ch., L'Administration au pouvoir, Calmann-Lévy, 1969 , págs. $168,169,174$, etc.).

(9) La interpretación clásica de nuestro Régimen local es la contenida en Adolfo Posada, Evolución legislativa del Régimen local en España (1812.1909), 
1) La concepción del Municipio como una entidad distinta y enfrente del Estado; entidad que en Francia tendrá hasta 1830 naturaleza privada (por mucho que hoy nos sorprenda), que, al igual que cualquier otra persona (física o jurídica), afirma su personalidad y libertad frente al poder político del Estado; naturalmente que esa singular configuración como sociedad privada le dejará un estrecho margen de actuación: administración de su patrimonio y police municipal.

2) La publificación del Municipio, que Posada Herrera proclamara en España frente al sistema francés (nunca tuvo entre nosotros plena vigencia la tesis del pouvoir municipal), se hace en base a una concepción de éste como unidad política separada y distinta del Estado. El Municipio será «natural», casi de origen divino. Sus fines serán peculiares y propios. Sus competencias, exclusivas. Su organización tangencial e independiente a la del Estado, como círculos que no se tocan, y menos se interpenetran. Es «otra esfera de intereses» $(9$ bis $)$.

Madrid, 1910 (especialmente en págs. 40 y sigs. y 70 y sigs.), a partir de la cual se han formulado unas versiones de nuestro Régimen local al modo francés, según el modelo napoleónico (legalismo uniformista, centralización, subordinación jerár. quica, sistema de alzadas, etc.), que-se dice-perdura entre nosotros hasta 1924 (Estatuto municipal). «Las Cortes de Cádiz escribió Posada-construyeron o más exactamente planearon el edificio político-administrativo de la España del siglo xIx y... hasta ahora», organización que se caracteriza por «el engrane, nada disimulado, de todas las instituciones locales en una jerarquia mecánica, según sistema de subordinación, que contiene el germen de la futura estructura administrativa cen tralizada, uniforme y simétrica, y las condiciones para un desarrollo del espíritu burocrático» (pág. 71). (Subrayado del autor).

García de ENTERría ha explicado esta configuración en base a la doctrina del pouvoir municipal (vid. fundamentalmente sus trabajos: «Fundamentos ideológicos del sistema municipal francés», en Revista de Estudios de la Vida Local, número 117, págs. 321.330; «La Provincia en el Régimen local español», en Problemas actuales del Régimen local, Sevilla, 1958, págs. 3-40; «Turgot y los orígenes del municipalismo moderno», Revista de Administración Pública, núm. 33, págs. 79-110, y en La Administración española, Madrid, 1960, págs. 119 y sigs.). Esta formulación de nuestro Régimen local se ha hecho contemplando fundamentalmente una de sus coordenadas fundamentales (el tema de la competencia) y olvidando quizá excesivamente la cuestión de la elección y representación, que fue sin duda a lo largo del siglo XIX la cuestión central.

( 9 bis) Testimonio legal expresivo de esta concepción es, por ejemplo, el Decreto de 21 de octubre de 1868, de Sagasta, en cuya justificación se lee: «Si el Estado, la Provincia y el Municipio han de ser las tres esferas concéntricas, de dimensiones diversas, dentro de las cuales se desarrolla armónicamente la política del país, es preciso que giren en el mismo sentido pero sin tocarse en su movimiento». Y la misma concepción en este alucinante texto del Proyecto constitu. 
Naturalmente éste es el esquema conceptual, con muchas quiebras en la realidad, llámense Jefes políticos, Alcaldes como agentes del Gobierno, poderes de tutela y aun de jerarquía de los Subdelegados de Fomento y después de los Gobernadores civiles; pero frente a ello, Milicias nacionales, caciques electorales y en definitiva el perpetuo pacto entre el Gobierno central y el cacique local. Esto, en la realidad. Pero la concepción del municipalismo, el esquema doctrinal, es el descrito, francés y centralista, a lo largo del siglo xIX (10).

cional de 1873, cuyo artículo 40 establecía este corte radical de «competencias»: «todo lo individual es de la pura competencia del individuo; todo lo municipal es del Municipio; todo lo regional es del Estado; y todo lo nacional es de la Nación» (recuérdese que estamos ante un proyecto federalista). He visto citada la primera de estas disposiciones en Niero, A., «La Administración y el Derecho administrativo durante el Gobierno provisional de 1868-69), en Revista de Occidente, octubre 1968. Estas promulgaciones legales son expresión de una concepción general. Naturalmente, lo dificil era, en un tal sistema, determinar el contenido de «lo municipal» o «lo regional» y mucho más difícil todavía que, sin tocarse, las tres esferas giren en el mismo sentido.

(10) Frente a esta tesis-que es la comúnmente admitida--debe dejarse constancia de un intento reciente de explicación del Régimen local español, que se aparta del tradicional: Gallego Anabitarte ha afrontado el estudio de la evolución y configuración histórica de nuestro Régimen local, a la luz no sólo de los textos positivos, sino también de los movimientos políticos e ideológicos que presiden nuestro siglo $\mathrm{xIx}$, y de las instituciones sociales y económicofinancieras intimamente unidas-y condicionantes-del Régimen local. Frente a la versión tradicional afirma: a) el tono autónomo y popular de nuestros Municipios, que se desprende del artículo 312 de la Constitución de Cádiz (principio de elección) y en varios textos del discurso preliminar (no obstante la presidencia del Jefe político que prevé el artículo 309 ) ; b) la realidad política de nuestro Ayunta. miento constitucional, construida por el autor sobre la institución única en el mundo occidental, de la Milicia Nacional (arts. 362 y 365 de 1812), y más tarde sobre el caciquismo. Sobre ambos pilares-democracia civil y democracia militarapoya su conclusión de que hasta 1845 nuestros Municipios no fueron en modo alguno pacíficos centros administrativos al modo francés, sino «auténticos centros revolucionarios y verdaderas repúblicas autónomas». La Ley de 1845 supone un profundo cambio; pero cuando, tras el corto renacer del Ayuntamiento constitucional (1854-56) y la evolución revolucionaria de 1868, se vuelve, en 1877, al modelo moderado y se acentúa la pérdida de autonomía local (intervención real en el nombramiento de Alcaldes), lo que se instaura-dice-no es la centraliza. ción, sino el caciquismo (vida local autóctona de los grupos privilegiados y poderosos que manejan las elecciones en «su zona» y con los cuales necesitan «pactar» los titulares del poder central). En resumen, las afirmaciones son, en primer lugar, «que puede haberse dado la auténtica centralización al modo francés cuando no ha existido un verdadero Estados; en segundo lugar, no se puede explicar un Régimen local sobre una «mera consideración abstracta de competencias», sino sobre el «poder»y el «orden socio-económico»; postula, por ello, una «desadministrativización» de la cuestión, de su tratamiento formal y legalista para volver al 
3) En esta rápida mirada por el siglo xIx llegamos a ese tournant de l'histoire que es la primera postguerra mundial. Triunfan en este momento y se consagran solemnemente en las leyes los mitos doctrinales que habían alentado la concepción municipalista a lo largo del siglo xix. Los Estatutos de CaLvo Sotelo son un claro testimonio: en ellos se acumulaban sobre los entes locales competencia tras competencia con el calificativo de «exclusivas» (artículo 150 del Estatuto municipal) (11); al mismo tiempo, sin embargo, como es bien sabido, se producía un proceso de signo inverso, en el que al amparo del propio Estatuto (12), la legislación sectorial del gas, de los transportes, de la electricidad y demás servicios públicos vaciaba progresivamente de contenido las solemnes declaraciones legales (13).

estudio de las Entidades locales como centros de poder y «escuelas de democracia». Tal es la tesis de Gallego Anabitarte, formulada en una comunicación al II Symposium de Historia de la Administración celebrado por el Instituto de Estudios Administrativos, Alcalá de Henares, noviembre de 1969, tesis que, naturalmente, está por demostrar, aunque tal parece ser el propósito del autor en un próximo libro que anuncia: Historia del Régimen local en sus textos, colección IEA. Posteriormente esta tesis ha sido formulada en unas «Notas histórico-juridicas sobre el Régimen local español (intento de revisión)», en REvista dE Estudios DE LA VIDA Local, núm. 166, págs. 265 a 274.

(11) De la doble significación de los entes locales (división administrativa del Estado y ente representativo de intereses propios y privativos), la segunda, esto es, la consideración de aquéllos como «otra esfera de interés», como algo separado y distinto del Estado, acabará por imponerse dogmáticamente. En efecto, como reacción frente al Régimen local de $1870-77$ en España se produjo, a lo largo del último tercio del siglo $\mathrm{xIx}$, un movimiento de corte romántico y iusnaturalista que sobre la base del carácter natural del Municipio defendia la más amplia autonomia local y afirmaba como lo propio y específico de éste la defensa de sus intereses propios, distintos y separados del Estado: los llamados «intereses peculiares», «intereses privativos». La consagración legal de éstos se propugnará primero en el proyecto Maura y se conseguirá en los Estatutos de Calvo Sotelo.

Como consecuencia de ello, se insistirá en el tema de la exclusividad de la competencia sobre aquellos ámbitos que constituyen sus «intereses peculiares», exclusividad que se reconocerá en el articulo 150 del Estatuto de 1924, si bien al amparo del articulo siguiente (151) se dejaba abierta la puerta a la competencia del Estado, en base al cual se fueron vaciando de contenido las amplias relaciones de fines contenidas en el texto legal como «competencias locales».

(12) En concreto, de su artículo 151, cuyo sibilino texto empezaba diciendo: «La competencia municipal no será obstáculo para la de los institutos y servicios análogos a los municipales dependientes del Estado...».

(13) Es conocido el estudio de García de ENTERría, sobre el servicio público de gas, en Problemas actuales de Régimen local, Sevilla, 1958, especialmente páginas 57 y sigs. Otras manifestaciones de la llamada «prevalencia de la publicatio estatal sobre la local, en Villar Palasí, J. L., La intervención administrativa en la industria, I. E. P., Madrid, 1964, págs. 237 y sigs. 
4) La Ley de 1945 se referirá a esta idea de la «exclusividad» en el artículo 7. al hablar de «las materias que la Ley no confíe expresamente a la exclusiva competencia de los Municipios...», pero, como señala Jordana, ni una sola vez a lo largo del resto del articulado se hace después esa declaración expresa (14). En concreto, el artículo 101 elimina tal cláusula de exclusividad y adopta el sistema de cláusula general, que ha sido largamente criticado. El proceso de vaciamiento de este artículo ha sido estudiado con exhaustividad por Albi (15).

5) Concluyamos, pues, esta esquemática evolución afirmando que con o sin declaración de exclusividad, el hecho es que el tema de la competencia local se plantea clásicamente según una concepción dualista, como «un círculo absolutamente exento y separado de las competencias del Estado» (16). Círculo que a su vez se partirá entre Provincia y Municipio (17). Esta concep-

(14) Cfr. Jordana, «Consideraciones actuales sobre la reforma de la Ley de Régimen local», en Problemas politicos de la Vida local, vol. IX, págs. 40 a 45.

(15) Albi, F., La crisis del municipalismo, Madrid, 1966, págs. 448 y sigs. Las conclusiones a las que llega Albi después de su minucioso análisis son altamente expresivas: «cada concepto, cada inciso de la profusísima enumeración de atribuciones, se enfrenta con una disposición especial paralela, que atribuye a los poderes centrales esa misma competencia, o que somete la función a intervenciones gubernativas de tal alcance e intensidad que no dejan para el Municipio ninguna posibilidad de acción independiente. Lo normal es que el precepto especial no se acuerde de que existe una previa base jurídica de competencia municipal, y que proceda como si esa competencia no existiera; en otros casos-los menos-se consigna alguna vaga fórmula de referencia a lo municipal-por ejemplo: "sin perjuicio de las funciones atribuidas al Ayuntamiento"-, pero el conjunto normativo se produce sobre la idea de la absoluta preponderancia de la acción estatal; no faltando diversos preceptos que reservan al Municipio una competencia reglamentaria, de hecho puramente teórica, pues ha de ejercitarse sobre la base de normas estatales que regulan con minuciosidad la materia correspondiente, sin que quede nada esencial por prever».

(16) García de Enterría, E., La Administración española, I. E. P., Madrid, 1964, $2 .^{a}$ ed., págs. 107 y sigs. Cfr., por ejemplo, Aucoc, L., Conférences sur l'Administration et le Droit administratif, París, 1885, I, págs. 103-104, o VIvien, Etudes administratives, 3." ed., Paris, 1859, tomo I, pág. 52.

(17) Ya Posada Herrera se refería a esta partición clara de sectores y competencias: «asi como la Nación-escribe-tiene intereses generales que comprenden toda la extensión del territorio, asi también la Provincia tiene intereses provinciales y la Municipalidad intereses locales, y asi como los intereses de la Nación deben estar representados y debe haber quien vele por ellos, de la misma manera los intereses de la Municipalidad y de la Provincia deben estar representados y tener sus defensores». (Posada Herrera, José, Lecciones de Administración, Madrid, 1843, tomo I, pág. 332). 
ción tripartita de la acción administrativa se manifiesta en los distintos sectores: enseñanza, caminos, abastecimientos, sanidad, beneficencia, etc. Todo ello es de sobra conocido y no es preciso insistir más.

Pues bien, como la doctrina ha puesto reiteradamente de manifiesto (18), es éste un planteamiento absolutamente en crisis. La Administración planificadora y programadora que estamos viviendo impone un nuevo sentido, una nueva visión del tema de la competencia, que es sin duda el quicio de la descentralización de nuestros días. También, por supuesto, se impone una revisión de los sistemas y cauces de participación (elección, representación) de los ciudadanos en el poder local (19), pero aquí nos limitaremos al primero de estos puntos y sólo marginalmente haremos alguna alusión general al segundo.

\section{LA NUEVA VISION DEL TEMA}

Creo que en el Régimen local hemos llegado al final de una etapa histórica que comenzó con la Revolución y que se cierra en nuestros días. ¡Cuán lejos estamos hoy de esa concepción brevemente descrita! Se apreciará sin esfuerzo si recordamos algunos rasgos que, a mi juicio, marcan la actual situación.

1. Comprensión unitaria de la Administración pública.

Administración central y local no pueden ser vistas como dos esferas o mundos diferentes, como organizaciones separadas e impenetrables que están en situación permanente de tangencia, sin mezclarse. Creo más bien que la Administración del Estado (en-

(18) García de Enterría, E., La Administración..., cit, pág. 121. En el mismo sentido se manifiestan García-TreviJano, J. A., «Titularidad y afectación en el Ordenamiento juridico español», Revista de Administración Pública, núm. 29, pág. 57, y Vallina Velarde, J. L. de la, Transferencia de funciones administrativas, I. E. A. L., Madrid, 1964, págs. 134-135.

(19) Sobre este último punto, vid. Bopuera OLIver, J. M., «El sistema representativo municipal», en Problemas politicos de la Vida local, vol. V, Madrid, 1965; del mismo autor, «La Provincia como cauce de representación política», en $R_{E}$. vista DE Estudios de la Vida Local, núm. 156, págs. 801 y sigs., y también Garrido Falla, F., «La participación popular en la Administración local», en Revista de Estudios de la Vida Local, núm. 154, 1967. 
tendido éste como «suprema institución de la comunidad nacional») es única, y su acción no debe ser «cortada» por sectores, sino «unificada» en unos programas comunes. En otros términos, la Administración, hoy, no puede ser el resultado de unas unidades que, como ruedas locas de un engranaje, giran cada una a su aire, sino como un «corpus organizativo» que al margen de las formales declaraciones de personalidad y autonomía necesitan ser integradas en una «tarea común».

Esta visión es, por lo demás, obvia : cada una de estas unidades, personas o círculos de personas, que integran la Administración pública (recuérdese el artículo $1 .^{\circ}$ de la $\mathrm{LJ}$ ) no actúa sobre sectores o mundos diferentes: el destinatario de su acción-el individuo, la sociedad-es, en todos los casos, el mismo; y a éste no le importa mucho que el matadero, el gas, los transportes urbanos o la iluminación de sus calles se la suministre el Estado, la Provincia, el Municipio o una Sociedad mixta que se forme con todos ellos (y con los mismos ciudadanos incluidos). Quiero decir con ello que lo importante son las tareas, los programas de actuación, y no quien los realiza.

\section{LA «NACIONALIZACIÓN》 DE LAS TAREAS.}

Debe destacarse en segundo lugar un hecho: los problemas se han nacionalizado. El fomento de los distintos sectores, las intervenciones administrativas o las prestaciones de bienes y servicios resultan hoy difícilmente planteables aisladamente a escala municipal o provincial; pensemos, por ejemplo, en los abastecimientos, mercados, hospitales y centros asistenciales, vivienda o enseñanza. La sagacidad de HAUR ou ya advirtió, a principios de siglo, que la misma police municipal, el núcleo más municipal del viejo pouvoir, constituía en las grandes comunidades urbanas un problema nacional (20). Y ello, tanto por factores de política administrativa de nuestro tiempo a los que ya me he referido (la Administración del Plan) como por razones de progreso técnico. Al proyectar hoy un servicio-un matadero, un mercado-hay que atender básicamente a los propios condicio-

(20) Hauriou, M., Etude sur la décentralisation, Paris, 1893, págs. 18-19. 
namientos técnicos, económicos, sanitarios, que exige una moderna instalación de estos servicios para que éstos sean rentables y adecuados, y no a un apriorístico criterio de «exclusividad» o de «obligación mínima». Un planteamiento racional de estos servicios debe hacerse actualmente acorde con el progreso tecnológico alcanzado en cada sector (sanitario, educativo, urbanístico, del transporte o de mercados centrales), y una vez éste elaborado, según los datos técnicos que arroje, determinar cuál es la dimensión territorial o de clientela que la prestación del servicio exige. Como consecuencia se determinará si el nivel a que se está prestando (municipal, comarcal, provincial, etc.) es el adecuado o si es conveniente transferirlo a otro nivel superior o inferior (21).

De otra parte, los «asuntos locales» son hoy, cada vez más, partes de un todo (el Plani nacional), determinados en función del conjunto (de la política general del país, de la región o de la zona). Por ello, la concepción debe ser unitaria, y los entes locales no pueden pretender, porque además de inviable sería perjudicial para su población, una utópica libertad y autonomía para decidirlos aisladamente: deben someterse al cuadro general que le marca el Estado (22). El escalón local (regional, provincial o municipal) concretará, dentro de ese marco, su programa. Pero éste tendrá un sentido cada vez más nacional, en el que es imposible decir dónde acaba lo estatal y dónde empieza lo

(21) No se puede olvidar que tales apriorismos-«intereses privativos», «obligaciones mínimas»-están contemplando una realidad sociológica que está hoy pro. fundamente transformada (las distancias son menores, la alimentación ha cambiado, las técnicas de producción o de prestación del servicio totalmente distintas, etcétera). Seguir aferrados a viejos esquemas o fórmulas es desconectarse de la realidad: ¿qué falta hace hoy en los pueblos un lavadero público? Este planteamiento se lo oí formular al profesor Meilán GiL en una de sus intervenciones en las sesiones del III Congreso Italo.Español de profesores de Derecho administrativo, celebrado en Santiago de Compostela, junio de 1970. Ha sido destacado este factor recientemente por GianNini, M. S., La región..., cit., pág. 30 .

(22) El Estado u otra Administración local superior (por ejemplo, los Planes regionales o provinciales en relación con los Municipios). Así, Marrín-Retontillo, Sebastián, «Planificación...», cit., ha hablado del «carácter en cierto modo subordinado que los Planes municipales of recen en relación con otros de mayor am. plitud y a los que en cierto modo la Administración municipal debe someterse», y más adelante se refiere a la «imposibilidad de concebir los Planes municipales como realidades independientes incluso en materias que pueden considerarse como de la más estricta competencia municipal» (págs. 76-77). 
local (23). Análoga dificultad aparece en el deslinde entre los «intereses peculiares de sus territorios» confiados a la Diputación provincial (artículo 5.ำ de la Ley de Régimen local) y los propios de los distintos Municipios sobre sus términos municipales, que son los elementos integrantes de aquél.

Todos estos condicionamientos, que son-quiérase o no-un dato innegable de biología histórica, empujan hacia la centralización, porque llevan a hacer planteamientos y programas nacionales. El Plan-ya lo hemos dicho-estataliza los fines y las tareas. A la estatalización de los fines sigue la estatalización de los medios, y puede constatarse cómo en los últimos años se ha producido en todo el mundo un progresivo debilitamiento de las Haciendas locales, que hoy trata de corregirse (24). La potencia financiera de algunos servicios personificados nacionales contrasta en nuestro país con la penuria de los servicios locales (compárense, por ejemplo, nuestros viejos hospitales provinciales con las modernas clínicas y residencias del Instituto Nacional de Previsión).

(23) Tal es la visión del problema que se recogia en la Ley de Presupuestos de 26 de diciembre de 1957, que transformó profundamente el sentido de las Comisiones provinciales de Servicios Técnicos. Dice su Exposición de Motivos: «se autoriza la formación de Planes provinciales de inversión... con lo que se con. :seguirá una descentralización a todas luces conveniente»; sin embargo «se conserva en un organismo central la facultad de decidir en último término sobre la aplicación de los fondos, ya que es preciso una visión nacional en su administración si se quiere lograr la más perfecta coordinación entre el Estado y las Corporaciones locales». Naturalmente, el gran riesgo de este planteamiento, si no se ajustan finamente las competencias, es la absorción de los entes locales (como efectivamente se produjo: vid. lo que se dice más adelante). Por lo demás, este planteamiento es general: en todos los paises, el Estado ha asumido la tarea de definir los programas de política general a medio y corto plazo y de establecer la serie de obje. tivos a alcanzar; por lo común, se han centralizado los medios financieros y se ha descentralizado únicamente la gestión, delegando en los gestores la facultad de adaptar en su caso el Plan general a los condicionamientos de tiempo y lugar. ( Vid. Meyers, F., «Problemas actuales de la Administración pública en Bélgica», Documentación Administrativa, núm. 100, págs. 78 y 79 , y lo que se dice en la nota siguiente).

(24) En dos recientes declaraciones de política general, en Francia y en los Estados Unidos, se ha aludido a este problema. En un discurso del Presidente Nixon a la Unión del pasado año (8 de agosto de 1969), hablaba éste de la nece saria «devolución» a los Gobiernos locales de una parte sustanciosa de las rentas federales; y como consecuencia de la declaración de política general de Chaban Delmas el 16 de septiembre de 1969 , se estudia en Francia en estos momentos un proyecto de «descentralización financiera» que el Gobierno remitió hace pocos meses a la Asamblea Nacional. 
3. El impacto de la programación y el proceso de decisión. La partición funcional de Competencia.

Al llegar a este punto, podríamos preguntarnos si es que acaso las técnicas de programación conducen hacia una inexorable centralización de las competencias y a un mayor vaciamiento de los entes locales en favor de la tecnocracia estatal. Ya hemos. aludido a este punto y hemos dicho que en un primer momento así fue efectivamente, y la experiencia francesa es un ejemplo. Pero posteriormente esa tendencia se ha tratado de corregir, como escribe Giannini, mediante un «lento pero continuo ajuste de las técnicas de programación», que devuelva a los sectores y entes locales interesados su papel de protagonistas (25).

Veamos cuál puede ser el camino de esa «nueva descentralización».

García de ENTerría señaló hace unos años cómo el futuro. del Régimen local no radica ya en un «sistema de poderes exclusivos», como pretendía el viejo municipalismo que arranca de la Revolución (tesis del pouvoir municipal), sino precisamente en el de los «poderes participados o compartidos» (26), tesis que desde entonces ha sido muchas veces repetida (27). Ahora bien,

(25) Giannini, M. S., La región..., cit., pág. 32.

(26) Cfr. La Administración..., cit., págs. 109 y sigs. Defiende García de Enterría la necesaria articulación del Estado y los entes locales mediante la delegación de competencias de aquél a éstos con la concesión simultánea de los correspondientes recursos económicos y la consiguiente asistencia técnica; y ello, evitando-diceque «la técnica subvencional, el llamado "compromiso de auxilios", en vez de ser concebido como una ayuda económica que el Estado presta al ente local para que éste pueda cumplir los servicios, lo sea inversamente, como una absorción directa de la realización del servicio por el Estado con una simple ayuda económica local» (cosa que ha ocurrido, según este autor, con los Planes provinciales) (obra citada, págs. 109.110.168). Por lo demás, al Estado corresponde como es natural la «unidad de dirección» y el control técnico, financiero y de eficacia en la realización de las tareas (págs. 159-161-162). Tal planteamiento es, por lo demás, común en la doctrina. Vid., por ejemplo, Rivero, J., Problemas..., cit., pág. 117: «las: antiguas delimitaciones entre "asuntos locales". abandonados a la descentralización y necesidades de importancia nacional dependientes de la Administración del Estado, son hoy en dia arbitrarias y poco coherentes. Sin duda, todo debe ser reconsiderado no tanto sobre la base de un reparto de tareas..., cuanto sobre la de una cooperación con miras a su ejecución».

(27) Vid., por ejemplo, Martín-Retortillo, S., «Planificación y Administración local», cit., págs. 98 y 99 , que se adhiere expresamente a ella; en el mismo sentido, Entrena Cuesta, R., «Instroducción al estudio de las relaciones entre la Admi- 
se trata de precisar cuál es el sentido de esa participación, esto es, en qué forma se comparten los poderes de decisión. Y es aquí, a mi juicio, donde está el quid de la cuestión y donde se impone un nuevo approach al tema de las competencias.

La partición de competencias, efectivamente, no puede trazarse hoy «por sectores», pero tampoco sólo a través de la técnica de la delegación del ejercicio de las mismas, que contra lo que se viene diciendo no supone descentralización alguna, ya que el «poder de decisión» queda en última instancia en manos de las autoridades centrales (28). No digo que la delegación no deba ser utilizada, sino que eso no es descentralizar.

nistración central y la Administración local», en Problemas politicos..., vol. II, páginas 121 y sigs., especialmente págs. 134 y sigs.

(28) La tesis de García de Enterría sobre la articulación de los entes locales con el Estado, a través de la «atribución o delegación de servicios (por parte del Estado) a los entes locales como corporaciones autonómicas encargadas de la gestión» dista mucho de estar precisada técnicamente. Habló este autor de «fórmulas colaborativas, preferentes, cumplidas mediante delegaciones expresas» (pág. 109), «sin :mengua de la planificación, unificación y dirección del Estado», que conservaría también amplios poderes de control técnico, jurídico y financiero (págs. 109 y siguientes y 159 y sigs.) y que podria ejercer «una fiscalización estricta» (pág. 113); en otros momentos habla de la necesidad de dotar a los entes locales para esta gestión de «una iniciativa y una responsabilidad amplias» (pág. 112), y finalmente matiza todas sus afirmaciones sobre esta genérica «fórmula colaborativa» haciendo notar que «dentro de sus contornos generales es posible configurar variantes de muy distinto alcance» (pág. 161). Citas todas ellas de La Administración española, Madrid, 2." edición, 1964. García de EnTerría apuntó a un camino, pero en ningún momento pretendió configurarlo técnicamente (quiero decir, juridicamente) en sus detalles (por ejemplo, régimen de autorizaciones o aprobaciones, existencia o no de alzadas, poderes jerárquicos de instrucción o modificación de los actos, avocaciones, sustituciones, etc.). Ahora bien, la descentralización depende justamente de «estos detalles», sobre los que es preciso pronunciarse para decidir si una «fórmula colaborativa» es o no una fórmula descentralizadora. Sorprende, por ello, que algunos de los continuadores de esta tesis hayan formulado, sin más, una equiparación entre la «delegación de servicios» y la descentralización (así, Manzanedo-Hernando-Gómez Reino, Curso de Derecho administrativo económico, páginas 105.106), equiparación, a mi juicio, más que dudosa a la vista del contenido que la delegación de competencias tiene en nuestro Derecho. Sobre el concepto técnico-juridico de la «delegación» y sus posibles contenidos, vid. Vallina VELARDE, J. L. de la, Transferencix de funciones administrativas, I. E. A. L., 1964, páginas 98 y sigs. Recientemente, González Navarro, F., en su minucioso estudio Transferencia del ejercicio de competencias administrativas, E. N. A. P., junio 1970, se pronuncia claramente por la concepción de la delegación como «transferencia de ejercicio». Creo que éste es el sentido más correcto, especialmente en el caso de transferencias de competencias entre la Administración central y la local, ya que en otra forma se daría lugar a una confusísima situación de competencias que quedarían atribuidas al mismo tiempo, pleno iure, a la Administración central 
Pienso que un moderno planteamiento de la descentralización debe hacerse hoy desde la perspectiva del proceso de decisión. Un correcto enfoque en la distribución de competencias para toda la inmensa acción prestadora de bienes y servicios que ha asumido la Administración moderna es hoy éste: no se trata de dividir las competencias por «materias» entre sujetos distintos y excluyentes, ni de «delegar» la gestión de unos sectores o servicios, sino de establecer unos «programas» comunes de acción en cuya elaboración y gestión participan el Estado y los entes locales; los planes o programas deberán ir acompañados de una objetivación de funciones (estructura de programa) y de un sistema paralelo de asignación de las mismas, que será al mismo tiempo una estructura de competencias. La asignación de competencia será una asignación pleno iure, como competencias propias que no serán, según ha escrito MarTíN-Retortillo, un mero «participar en unas funciones delegadas que el Estado pueda encomendarles..., sino un auténtico y propio Spielraum que se les reconoce en las propias formulaciones planificadoras» (29).

Esta participación de las Corporaciones locales puede producirse en un doble plano (30).

y a los entes locales. Vallina Velarde, no obstante el amplio contenido que da a la figura de la delegación entre entes (no sólo transferencia de ejercicio, sino atribución ex novo de una competencia paralela a la del ente delegante) acepta el hecho de que en estos supuestos «el Estado podrá reservarse mayores poderes que los simples de tutela $y$, por tanto, fiscalizar más acentuadamente... y dirigir con carácter general la actuación de los mismos», lo cual-dice-《viene a establecer una relación de seudo-jerarquía» (Transferencia..., cit., pág. 14.8). Es obvio que tales poderes encierran en el fondo una reserva de decisión a favor del delegante, que en modo alguno es compatible con la descentralización. Asi lo entiende también Martín-Retortillo, S., «Planificación y Administración local...», cit., página 48. Una crítica a esta figura de «delegación» entre el Estado y las Corporaciones locales fue hecha también por ENTrENa, R., «Introducción...», cit., pág. 135. En fin, sobre el concepto y las notas definitorias de la descentralización me remito a lo que he escrito en mi estudio «Realidad y dogmática...», cit.

(29) «Planificación...», cit., pág. 48.

(30) Dejo fuera el plano de la elaboración del Plan. Ha sido éste un aspecto del proceso planificador español que ha sufrido duras críticas por parte de la doctrina (vid., por ejemplo, Manzanedo.Hernando-Gómez Reino, Curso..., cit., pá. ginas 103 y sigs. y págs. 113 y sigs.). El tema no puede ser despachado con afirmaciones generales, como a menudo se hace. Sería necesario estudiar en detalle las caracteristicas del Plan, su marco geográfico (provincial, regional o nacional), los tipos de medidas que supone, las elecciones que implica, magnitudes en que se expresa, etc., para decidir sobre el papel que las Corporaciones locales, en cuanto 
A) A nivel de la decisión: porque los Planes, correctamente elaborados, constituyen un diseño de la actuación en el que caben diversas opciones alternativas, en el que hay todavía muchas cuestiones que dilucidar, muchas decisiones a tomar. Pues bien, esas decisiones concretas (pensemos, por ejemplo, en materia de reordenación agraria, en la que hoy tienen tan poca intervención los entes locales; en la determinación de núcleos de expansión o de centros de interés turístico; o en la localización de los centros educativos, asistenciales o deportivos, etc.) pueden y deben corresponder en muchos casos a los entes locales y no siempre a los órganos centrales del Estado. Se opera así la sucesiva «individualización de la decisión» a través de la elaboración-en el cuadro del Plan nacional-de programas singulares en cada una de las circunscripciones territoriales y en cada uno de los sectores (agricultura, sanidad, comunicaciones o turismo). Es en esta «concreción» donde se debe establecer y garantizar hoy la «exclusividad» de la competencia de los entes locales, esto es, la garantía de participación de los ciudadanos, participación-directa—que ha de ser necesariamente menor en la concepción del Plan general y progresivamente creciente a medida que la decisión se va concretando e individualizando en la realidad; una precisión importante: tales decisiones no pue-

tales, están llamadas a jugar en su elaboración. Quiero decir que antes de pronunciarse aprioristicamente sobre la relación Plan.entes locales, en lo que a su elaboración se refiere, habría que hacer un detenido análisis sobre las diferentes técnicas y modelos planificadores. Hacer otra cosa es poner la carreta delante de los bueyes. Creo, en cambio, que, cualquiera que sea el modelo utilizado, a la Administración local (una nueva Administración local, no la de viejo cuño) debe corresponderle una importante misión en cuanto a la gestión de los programas (no pura ejecución, sino titularidad de funciones y adopción de decisiones). Coincido, por ello, plenamente con Martín.Retortillo, cuando escribe: «las Administraciones locales deberán colaborar adecuadamente, es cierto, en la elaboración del Plan; sin embargo, su papel fundamental creo debe actualizarse en la fase de su ejecución: bien entendido, además, que no se trata naturalmente de una simple ejecución material, sino una ejecución a realizar por las Administraciones locales sobre la base de una serie de opciones previstas y ordenadas en el Plan, dentro del marco de posibilidades que el mismo deberá reservar precisamente a las Administraciones locales» (en «Planificación...», cit., pág. 100). Es justamente en estos términos cómo la cuestión se plantea en el texto. Vid. también, sobre el tema, el trabajo de Pérez Orea, «La participación de los entes locales en la planificación del desarrollo económico», en Revista de Estudios de La VIDA Local, núm. 145, 1966, y lo que se dice en la nota siguiente. 
den ser revocadas ni sustituidas por los órganos centrales (31). Así, la descentralización puede ser hoy entendida sobre los distintos niveles de la decisión en el proceso de adopción de éstas. Esa es hoy su «competencia exclusiva», y no unos inencontrables «fines peculiares».

Esto no es ni más ni menos que la aplicación a las relaciones entre la Administración central y la local de los modernos sistemas de gestión integrada, que se han hecho posibles por el desarrollo en los últimos años de los «bancos de información», que permiten tanto en el sector privado como en las Administraciones públicas tomar las decisiones que resulten más coherentes y adecuadas a la situación general del mercado o a la política general del Gobierno, respectivamente (32).

Tratemos de explicar esto esquemáticamente.

Si se contempla a la Administración pública como una estructura organizativa con sentido unitario (el sentido que le dan unos programas comunes) cabe perfectamente, sin atentar contra la legítima autonomía de que deben gozar los «centros» en sus distintos niveles y modalidades (central, local, institucional, corporativa), intentar la aplicación a ella (como a cualquier organización : conjunto de medios personales y reales para conseguir un objetivo común) de los mecanismos modernos de adopción de decisiones que permiten maximizar los resultados. Se

(31) En esta regionalización o provincialización del Plan general hay dos aspectos en la preparación de la decisión: 1. Elaboración, propuesta, estudios técnicos: la autoridad central, con sus equipos técnicos, analiza las proposiciones, proyectos u objetivos, etc., que formulen los distintos entes locales o representaciones sectoriales y ofrece soluciones alternativas. 2. Los interesados, representantes y elegidos, en áreas regionales o provinciales, toman las decisiones dentro de su nivel. 3. En caso de desacuerdo, el Gobierno arbitra.

(32) Vid. Ecole Supérieure de Guerre, «Rapport sur l'introduction des méthodes et moyens d'action modernes de gestion dans l'Administration», en La Revue Administrative, núm. 135, 1970, págs. 349 y sigs. También, Самacho, A., Centralization and Decentralization of Decisión Making Mechanisms: A General Model, Chicago, Northwestern University, mayo 1970; y del mismo autor, «Una organización y su actividad: la Planificación económica. Centralización versus Descentralización», ponencia presentada al Seminario que sobre este tema tuvo lugar en el Instituto de Estudios Administrativos, enero 1971. Quiero dejar aqui constancia de mi agradecimiento al doctor CAmacho, profesor español en la Northwestern University de Chicago, con el que he tenido la oportunidad de dialogar ampliamente sobre estos temas, y del que he escuchado interesantísimos juicios que .aquí recojo. 
trata con ello de llegar a las decisiones óptimas. La planificación no es, en definitiva, sino el largo «proceso encaminado a determinar las decisiones óptimas que los miembros de la organización han de tomar» (33). Este proceso tiene una serie de etapas: recogida de datos, transmisión de informaciones de unos miembros de la organización a otros, realización de análisis y cálculos (coste, beneficio, etc.), valoración y estimación preferencial de objetivos, y finalmente adopción de decisión.

No es necesario entrar ahora en una exposición detallada de alguno de estos «modelos», por lo demás cambiantes según los sectores y el tipo de organización de que se trate. Diré únicamente que los autores distinguen siempre dos tipos de variables: «variables exógenas» (aquella sobre las que los agentes de la organización no tienen control alguno y sólo pueden observar: el mundo externo) y «variables internas» (aquellas acciones que pueden ser tomadas y que dependen y están bajo el control de los miembros de la organización). Así, en materia turística, por ejemplo, serían variables exógenas el clima y orografía, la política turística o monetaria de los países productores de demanda turística, la competencia de terceros, la educación, tradición y ambiente del lugar, etc.; pertenecerían en cambio al segundo grupo la elección de zonas preferentes, medidas de promoción de transporte aéreo con determinados puntos (construcción de aeropuertos, establecimiento de líneas regulares, etc.), la realización de campañas de propaganda turística en el exterior, una posible política de crédito hotelero, etc.

Pues bien, toda decisión exige un conocimiento lo más completo posible de sus numerosísimas variables determinantes (tanto exógenas como internas). Ahora bien, ocurre que toda esa información está normalmente muy repartida entre los agentes de la organización (cada uno conoce una pequeña parte de ella). Por ello, es una necesidad universalmente sentida en todas las grandes organizaciones-por supuesto, también en el Estadola constante comunicación y transmisión de información entre sus miembros, la creación de corrientes de información, ya que

(33) Camacho, A., «Una organización...», cit., pág. 4. 
sólo en base a ella podrán adoptarse decisiones correctas. Lo que ocurre es que muchas veces la información sólo va de la periferia al centro, y no a la inversa, bien porque el centro guarda celosamente la información (es el secreto de su poder), bien porque la periferia es incapaz de recibirla y valorarla.

Por otro lado, hay determinados ámbitos de decisiones en que la coordinación de unas con otras es fundamental, mientras que en otros campos las decisiones singulares son menos interdependientes. Típico ejemplo del primero es, por ejemplo, la política industrial, la instalación de complejos industriales, donde la planificación y coordinación son totalmente necesarias para evitar «deseconomías externas»; campos, en cambio, de gran autonomía e independencia en la decisión, de entre los contenidos en el artículo 243 de la Ley de Régimen local, pueden ser la defensa de la propiedad monumental o de la tradición cultural en una zona determinada, la actividad benéfica $o$ asistencial, el turismo, e incluso la ordenación agraria o forestal. En estos últimos campos, además, son decisivos los factores que hemos agrupado bajo el nombre de «variables exógenas», datos e informaciones que son difíciles de controlar y que se aprecian sobre todo in situ.

También en principio y sin valor absoluto puede afirmarse que en aquellos casos en que la «información» aparece como factor más relevante, especialmente aquella información del mundo exterior que está integrada por múltiples variables exógenas dispersas, el sistema a adoptar sería el descentralizado; lo mismo en aquellos campos en que es difícil transmitir la información desde los agentes que la recogen directamente a la oficina central. En estos supuestos, si se adoptase un sistema de centralización, o bien resultaría costosísima la transmisión de la información, o bien ocurriría que el centro tomaría decisiones arbitrarias y alejadas de la realidad. Por el contrario, hay otros aspectos o cuestiones que sólo desde el centro pueden juzgarse rectamente, pues exigen una visión de conjunto y un conocimiento de la coyuntura, nacional e internacional, que difícilmente pueden llegar a tener los agentes periféricos, y que además no resulta transmisible a ellos. 
Aun a costa de simplificar demasiado las cosas, podría quizá concluirse que, desde el punto de vista del proceso de decisión, la elección de un sistema centralizado o descentralizado no puede hacerse a priori, sino a la vista de la naturaleza y condicionamientos que acompañan la decisión en la materia concreta de que se trate. El criterio es simple: que decida aquel que está en mejores condiciones para decidir. En aquellos casos en que el conocimiento del mundo externo es decisivo y el intercambio de información (del centro a la periferia) es posible, resultará conveniente adoptar un sistema descentralizado, mientras que cuando la información resulta intransmisible (por razones técnicas o políticas) o cuando lo decisivo sea la coordinación de acciones, lo lógico y adecuado será centralizar la decisión. Ello explica una experiencia bastante universal : los países-o las empresas-en vías de desarrollo se ven casi fatalmente empujados a la centralización, porque la rentabilidad de muchas de sus inversiones y la eficacia de sus directrices de política económica dependen en gran medida de una estrecha coordinación entre las mismas ( 33 bis).

Por otro lado, lo que normalmente acontecerá es que el establecimiento de determinadas magnitudes y los cuadros generales de actuación sólo podrá llevarse a cabo por el Estado. La concepción de la política debe ser unitaria y pertenece al Estado (Plan: determinación del cuadro general de actuación, que

(33 bis) Esto ha ocurrido-creo-tanto en los Estados como en las grandes organizaciones privadas. $Y$ sólo después de una larga etapa de expansión y desarrollo éstas han buscado fórmulas descentralizadoras de la decisión. Cfr. el Informe Demonque-Lofficier, Presidente y Vicepresidente de la Societé des Ciments Lafarge sobre «L'apport des méthodes de gestion entreprises privées», en Conféren. ces sur la rationalisation des choix budgetaires, París, 1969. Creo, por ello, que hay a veces bastante superficialidad, cuando no fácil demagogia, en algunas críticas que se han hecho al «centralismo» de nuestros Planes de Desarrollo, los cuales, al margen de otros aciertos o desaciertos en los que no entro, han sido planteados en este punto de acuerdo con la situación general-económica e ins. titucional-del país. Más aún: de la única forma, quizá, que, para empezar, era posible plantearlos. Es cierto, sin embargo, que quizá ha llegado ya el momento de cambiar el sentido de la marcha. El Plan no debe seguir siendo un instrumento legal de absorción de competencias y tareas por el Estado, sino más bien «un sistema de comunicaciones y cálculos encaminado a proporcionar a cada uno de los miembros de la organización la información adecuada para determinar la decisión correcta a tomar»(Cаmacho, A., loc. cit., págs. 9 y sigs.). 
exige una «visión» de futuro y una «elección» de metas y objetivos tendentes a la configuración de esa visión). El Plan es, sobre todo, un cuadro de magnitudes y líneas basicas, que no implican, per se, decisiones concretas ni determina la acción administrativa. El Plan ha sido hasta ahora muy poco operacional. La participación de los entes locales en la determinación de ese cuadro general de actuación, de grandes magnitudes, no parece muy necesaria (más lo es en este orden la participación de las representaciones económico-sectoriales). En cambio, la intervención de los entes locales resulta insustituible, a mi juicio, en la determinación de los programas operativos, referidos a las distintas circunscripciones territoriales.

Los «sistemas informáticos de gestión integrada» (IMIS, Integrated Management Information Systems) consisten, pues, esencialmente, en un proceso doble: 1) una acción permanente de «información de la decisión», tanto a la hora de elaborar el Plan general como en la elección de las opciones singulares en él contenidas; y 2) un proceso de análisis de las diferentes variantes de decisiones posibles desechando aquellas que no corresponden o que se oponen a las finalidades previstas en el Plan general, y seleccionando en cambio aquellas otras que lo cumplen; de entre estas últimas, los órganos de decisión (en nuestro caso, los entes locales) elegirán la que consideren más adecuada (34).

Cabe también, naturalmente, que a la vista de los procesos de análisis de las decisiones singulares realizados en las unidades no centrales (Administraciones locales) se proponga a los órganos centrales (Gobierno) la modificación o reforma del Plan general y la adopción de aquéllas. En cualquier caso, se trata de llegar a una decisión que sea en primer lugar una decisión «informada» (adoptada en base a una información lo más completa posible sobre los condicionamientos de todo tipo que le acompañan : políticos, financieros, tecnológicos, sociológicos, etc.; información realizada de modo sistemático y mediante ordenadores,

(34) Vid. sobre el tema, el número monográfico de Economie Apliquée, «Archives de l'ISEA», 1969, núm. 4, dedicado a la Informática y a los modernos procedimientos de gestión, y especialmente, por lo que al tema de la descentralización se refiere, el artículo de BonNarD, M., «Réforme administrative régionale, et Informatique», loc. cit., págs. 719 y sigs. 
no a través de «impresiones» más o menos personales e infundadas de los titulares del órgano decisor); y en segundo lugar, que sea una decisión «integrada», esto es, coherente y armónica con el conjunto de la acción estatal (o incluso supraestatal, como ocurre actualmente entre los «seis» del Mercado Común para determinados sectores).

¿Cuál va a ser eli impacto de estas nuevas técnicas de gestión sobre la dinámica centralización-descentralización? Mi opinión es que los actuales sistemas de adopción de decisiones y el empleo de la Informática acrecentarán, si son bien utilizados, la capacidad de decisión razonada y responsable de los entes locales (35), aunque es evidente que también pueden ser utilizados con una finalidad centralizadora y absorbente (36). Pero en cualquier caso ese va a ser en los próximos años el nuevo camino de la descentralización (37).

Por lo demás, debe decirse que para la mayoría de las tareas administrativas o de los programas de gobierno, la instancia de decisión local debe situarse hoy en las Provincias (o en su caso, para determinados planes económicos, en la Región) ; el Munici-

(35) «Rapport...», cit., pág. 350: «ce qui manque souvent à l'heure actuelle au responsable administratif et ce qui restreint sa liberté d'action c'est de ne pas avoir les moyens de déterminer ces critères. Pour éviter de prendre une décision qui serait à priori, il a une tendance normale à se retourner vers l'échelon supé. rieur et à se contenter d'être un rouage passif et irresponsable. En fait l'informatique peut être le moyen qui facilitera la déconcentration et la décentralisation».

(36) «Rapport...», cit.: «l'ordinateur peut être aussi bien si on n'y prend garde l'agent de la centralisation que celui de la décentralisation. C'est ainsi que dans de nombreux services (sécurité sociale par exemple) les matériels et le personnel des «centraux» ont été mis en place et le fonctionnement actuel fait tout remonter vers l'Administration centrale» (ibidem).

(37) Cuando estaba terminando de redactar este trabajo, me he encontrado, leyendo el reciente libro de DebBasch, L'Administration au pouvoir, 1969, páginas 214.215 , el siguiente texto que coincide exactamente con el planteamiento que aquí se hace, aunque el contexto es más general y sólo de pasada se refiere a la centralización: «una sociedad industrial avanzada no puede satisfacerse con técnicas de reforma administrativa que convenían al siglo pasado. Una transformación profunda de los métodos de approach al problema se impone. Hasta aquí se ha venido pensando la Administración, en Francia, en términos de constitución admi. nistrativa; sería necesario comenzar a considerarla en función de técnicas de organizacion. Muchos antiguos debates quedarian superados. El conflicto entre centralización y descentralización, el «corte de materias» entre el Estado y las Corporaciones locales deviene hoy artificial...»; es, pues, preferible analizar «le rôle des collectivités locales dans ce processus plutôt que de leur attribuer des pouvoir de décision théoriques». 
pio, salvo en los casos de grandes comunidades urbanas, ha quedado hoy pequeño para estas misiones de servicio público.

B) A nivel de la ejecución: porque una cosa es la concepción del Plan o programa, que es siempre unitaria y corresponde al Estado (o, en general, al ente situado en el nivel adecuado -provincial o regional-para elaborar un Plan coherente según la materia de que se trate: no todos los programas requieren idéntico marco geográfico), y otra su ejecución; ésta puede y debe quedar también, con la correspondiente asistencia financiera y técnica del Estado, a cargo, en muchos casos, de las Corporaciones locales.

No siempre, sin embargo, deberán ser confiadas las tareas de ejecución a los entes locales; cuando éstas exijan un alto grado de capacidad técnica y de gestión, pueden seguir encomendadas a los servicios periféricos de la Administración del Estado, que son los que reúnen las mejores condiciones para llevarlas a cabo. Ahora bien, cabe pensar igualmente en una cierta «comunicación» de personal entre la Administración central y la local, que permita la asistencia técnica necesaria de aquélla a ésta mediante la colaboración temporal de técnicos y expertos del Estado en proyectos concretos encomendados a los entes locales, fórmula que con resultados muy positivos viene aplicándose en Francia desde hace bastante tiempo (37 bis). En estos casos los servicios periféricos (Jefaturas de Obras Públicas, de Montes o de Industria) se considerarán-a estos efectos-adscritos y dependientes del ente local, esto es, afectados a su servicio (38), pero-entién-

(37 bis) Vid. Portiglia, M., «La Direction Départamentale de l'Equipement au service des collectivités locales», Bulletin PCB, octubre 1970, págs. 41 y sigs. En el mismo sentido, Lenuédé, M., «Le Parc des Ponts et Chaussées au service des collectivités locales», en la misma revista, págs. 49 y sigs.

(38) Delion, A., («Réforme administrative: déconcentration et unité d'action», Droit Administratif, núm. 1, 20-I-1963, págs. 9-10), ha puesto de manifiesto cómo sería imposible la transferencia de tareas a los entes locales si no se refuerzan sus cuadros técnicos. Ahora bien, no se puede pensar en la duplicación de los servicios, sino más razonablemente en la afectación, en la ejecución de un programa determinado, de los servicios estatales periféricos al ente local. Esto como norma general. Sin embargo, en las grandes aglomeraciones urbanas o en los niveles superiores de la Administración territorial (nivel provincial y en su nivel regional) parece conveniente que la descentralización vaya acompañada-o mejor, precedida-de una reforma institucional que suponga un adecuado equipamiento 
dase bien-será el ente local (normalmente las Diputaciones) el competente para adoptar las decisiones que proceda a lo largo de la ejecución del programa.

Debe precisarse que, tanto en uno como en otro aspecto (decisión y ejecución), aun cuando la acción regional o provincial constituya simplemente una «parte» de un Plan nacional de conjunto, aun cuando sea costeado en su gran mayoría o en su totalidad con fondos del Estado, y aun cuando su ejecución esté encomendada a los servicios periféricos de éste, hay que entender - si se quiere descentralizar-que la titularidad de la función de la obra o servicio, y en general del programa de que se trate, corresponde al ente local (Municipio, Provincia o, en su caso, Región). No hay aquí delegación alguna, sino un auténtico y propio campo de acción que la norma aprobatoria del programa ha reservado al ente local (39). Este será, por ello, quien forma, controla y gestiona el presupuesto, quien contrata y paga, nombra o autoriza, aprueba o deniega solicitudes, expropia o acuerda subvenciones, en una palabra, quien decide, a ese nivel, cuantas cuestiones se presenten. Naturalmente, todo ello dentro del cuadro de directrices jurídicas, técnicas y financieras que el Estado haya señalado para cada tipo de proyecto (sea éste industrial, turístico, sanitario o educativo).

La cuestión es: ¿pueden confiarse estas tareas a los actuales entes locales?, ¿será conveniente la creación de unos entes ad hoc, de naturaleza mixta y con participación representativa para la gestión de los programas más complejos? En cualquier caso, parece evidente la necesidad de un previo potenciamiento de nuestros entes locales, que hoy serían incapaces, en la mayoría de los casos, para asumir estas tareas.

\footnotetext{
técnico de las Administraciones locales. (Vidi en este sentido Pallez, G., «Vers des institutions d'agglomeration», en Collectivités locales, París, 1970, págs. 33.34).

(39) Los entes locales constituyen asi-en un sistema de descentralizacióncentros autónomos de poder en el seno del Estado (Institución), independientes de la Administración central en el ámbito de su competencia. La competencia local debe ser hoy la reserva legal de participación en la acción del Gobierno, a favor de los ciudadanos afectados, con referencia a una zona territorial o a un sector material de la vida del país.
} 


\section{NeCesaria flexibiLidad del Ordenamiento.}

Evidentemente, un sistema flexible de distribución de competencias como aquí se presenta, requiere una instrumentación jurídica adecuada. Meilán hablaba recientemente de la necesidad de «dar mayor fluidez al ordenamiento de las competencias» (40). Frente a la exigencia de ley formal para la atribución de competencias a las distintas Administraciones, que es la solución clásica (41), hoy se postula un sistema abierto y diversificado, susceptible de ser actualizado en algunos supuestos por Decreto del Gobierno o incluso por concierto entre éste y los entes locales, con la consiguiente elastificación del principio de irrenunciabilidad de la competencia, que no puede ser entendido rígidamente, pues ello supondría cerrar el paso a fórmulas eficaces de colaboración como los «contratos de Plan», las «competencias concertadas» o los «acuerdos de delegación» $(42,43)$.

(40) Conferencia pronunciada en Orense sobre Problemática actual de las Administraciones locales, III Jornadas Administrativas Gallegas.

(41) Vid. por todos, Vallina Velarde, J. L. de la, Transferencia..., cit., páginas. 142.143, 146-147.

(42) Esta nueva orientación, mucho más dúctil y flexible que la tradicional, se aprecia, por ejemplo, en la última declaración de política general del PrimerMinistro francés, que con relación a las Corporaciones locales afirmaba: «Desde 1.- de enero próximo, relaciones de un nuevo tipo, de carácter contractual, se harán posibles entre el Estado y las Corporaciones locales, ya se trate de Municipios en vías de expansión para la realización de sus operaciones de urbanismo e:1 el marco de zonas de ordenación concertada, o bien-a través de contratos. plurianuales - en el caso de communautés urbaines para el conjunto de sus operaciones mayores de equipamiento»; la finalidad de estos «contratos de Plan» que supondrán una verdadera atribución de competencias concertadas, consiste en «transferer progressivement aux Départements et aux Communes - et tout spécialement à celles qui, en se regroupant, auront renforcé leur capacité de décisiondes secteurs entiers de compétence actuellement exercées par l'Etat, ainsi que, bien entendu, les ressources correspondantes》. (Declaración de M. Chaban Delmas, Le Monde, 17-X-1970). Un problema interesante es la calificación dogmática de esta transferencia; a mi juicio, no es una simple delegación (transferencia esencialmente revocable del ejercicio de determinadas competencias administrativas), pues. to que: 1) entiendo que en modo alguno se crea entre el Estado y el ente local una relación de dependencia jerárquica en la materia objeto de transferencia, con: consecuencias importantes en cuanto a la posibilidad de alzadas: a diferencia de lo que es propio de la delegación-la alzada necesaria, cuya resolución no puede delegarse (art. 118 de la Ley de Procedimiento administrativo)-, en estos casos.. entiendo que no procede alzada ante el Estado; y 2) es evidente, a mi juicio, que tales transferencias no son libremente revocables, como es propio de toda delegación. En cuantoi a si lo que se transfiere es la titularidad o su ejercicio, la cuestión: 
Más aún: pienso que difícilmente se puede llegar a establecer una línea de separación de las funciones (competencias funcionales) uniforme para todos los sectores y para todos los entes locales de un mismo tipo, pues ello evidentemente dependerá, primero, de la naturaleza del programa, y segundo, de la propia capacidad del ente local para asumir responsabilidades. Es patente, por ejemplo, que no todas las Provincias o Regiones espanolas tienen el mismo nivel y capacidad de asumir posibles tareas descentralizadas. Un estatuto uniforme sería la artificial igualación de cosas desiguales. La delimitación de funciones, al menos por el momento, debe ser elástica y susceptible de adaptación a cada situación por la norma de aprobación del plan o programa (en muchos casos será una ley, pero en otros no) (44).

\section{La renovada potenciación de los entes locales como «Instancias» de la Administración general del país.}

Hemos visto cómo la progresiva centralización material de los

\footnotetext{
puede resultar dudosa. Sólo con estas salvedades iniciales, que exigirian un estudio mucho más profundo, ahora imposible, puede aceptarse la expresión «acuerdos de delegación», en la que alguna vez se ha pensado, para configurar jurídicamente este fenómeno en nuestra reforma en marcha del Régimen local. Me remito, sobre estos puntos, al reciente y fino estudio de González Navarro, F, Transferencia del - ejercicio de competencias administrativas, Alcalá de Henares, junio 1970. Sobre la cuestión de los recursos procedentes contra los actos dictados por delegación, vid. también Vallina Velarde, Transferencia..., cit., págs. 127 y sigs.

(43) Entre nosotros, Entrena Cuesta, R., hace ya años, se refirió a estas fórmulas de colaboración de carácter contractual entre el Estado y las Corporaciones locales (relaciones de colaboración, relaciones de cooperación, en la termino. logía de Entrena), en «Consideraciones sobre la teoría general de los contratos de la Administración», Revista de Administración Pública, núm. 24, 1957, páginas 39 y sigs., especialmente págs. 67 y sigs., y posteriormente en «Introducción al estudio de las relaciones entre la Administración central y la Administración local», en Problemas..., cit,, vol. II, págs. 139-140-141.

(44) Es justamente esta posibilidad de adaptarse a cada caso (capacidad finan-ciera, estructuras orgánicas y competencia técnica de cada ente) lo que hace especialmente útiles en estos momentos de transformación de la Vida local las fórmulas de «concierto», que han sido hasta ahora muy bien recibidas por los comentadores: «l'idée de contrats de plan-escribia recientemente $P$. Sudreau-entre les grandes collectivités et l'Etat qu'a lancée derniérement le premier ministre est itrès séduisante», pues permite modular en cada caso la relación. (Le Monde, $14 \mathrm{de}$ octubre de 1970). Tal es también, como se sabe, el sistema inglés y el que en .muchos casos se ha venido empleando en Italia. (Cfr. Vallina Velarde, J. L. de la, Transferencia..., cit., págs. 148-149).
} 
últimos años, fruto de la centralización financiera y del monopolio de la capacidad técnica por parte del Estado, se ha producido, de hecho, al margen de las declaraciones legales. No parece que ninguno de estos tres factores condicionantes de la centralización (nacionalización de los problemas, centralización financiera y desarrollo tecnológico) puedan ser eliminados de nuestra sociedad (45). Hemos visto también la necesidad de un previo fortalecimiento de los entes locales (por lo menos de algunos) si se quiere un día descentralizar sensatamente. Es preciso buscar el camino para esa potenciación de los entes locales, y para la mayor parte de los sectores (gestión urbanística, sanidad, abastecimientos, grandes servicios públicos, educación, asistencia social, turismo, etc.) la vía de esa revitalización de los entes locales no. está en el mantenimiento a ultranza de un «municipalismo», sino al contrario, en la consideración de los entes locales en cuanto unidades administrativas integradas por la ley como «instancias»o instrumentos de la acción del Estado, significación ésta de vieja raigambre pero muy olvidada hasta fecha reciente (46).

(45) Cfr. García-Trevijano, J. A., «La autonomia municipal: aprobaciones y procedimientos bifásicos en el Ordenamiento español», en Revista de Derecho Privado, tomo L, 1966, pág. 749.

(46) Es bien conocida la doble serie de funciones que según la concepción tradicional se han atribuido siempre a los entes locales, de un lado como división administrativa del Estado, y de otro como representantes de los intereses locales, que se consideran propios y exclusivos. Posada Herrera, Lecciones de Adminis. tración, Madrid, 1843 (sobre las atribuciones de los Ayuntamientos); ORTIZ DE Zúñıga, M., Elementos de Derecho administrativo, Granada, 1842, págs. 101-102 (so. bre atribuciones de las Diputaciones). Modernamente, Jordana de Pozas, L., «Consideraciones actuales sobre la reforma de la Ley de Régimen local», en Problemas politicos de la Vida local, vol. IX, págs. 37 a 39 . He aludido ya al triunfo doctrinal de la concepción municipalista que ve a los entes locales como «entes representativos de intereses privativos», como «otra esfera de intereses distinta del Estado». Con ello, quedó olvidada, desdibujada, esa otra dimensión de los entescomo instrumentos de acción del Estado. A esta dimensión de los entes locales. -y con mayor razón de los institucionales-se ha referido, sin embargo, nuestra. mejor doctrina. Dos testimonios muy expresivos pueden ser recordados: PoSADA Herrera y Fernández de Velasco. «En las municipalidades-escribe el primeroencontramos dos caracteres distintos, a la vez que muy importantes. Un Ayunta. miento puede considerarse o como una división administrativa enlazada con todas las demás que tienen hechas el poder central o como el representante de los intereses de la localidad. Como división administrativa el Ayuntamiento está encargado de aplicar las leyes generales de los individuos que están dentro de su territorio». (Posada Herrera, J., Lecciones..., cit., pág. 389). En ese «aplicar las. 
Se trataría, como dice Martín-Retortillo, siguiendo a GarcíA DE ENTERRía, «de encomendarles la propia gestión periférica. de buena parte de la actividad administrativa, independientemente de la competencia genérica que en relación con ella pueda. estar atribuida al Estado» (47).

Nótese que es ésta una vía completamente distinta a la anterior, ya que en principio se configuraría como una estricta delegación (no como poder propio) con todo lo que ello significa: vinculación jerárquica, alzadas, poderes de instrucción y dirección, avocaciones, etc.

Esta articulación de los entes locales como «agencias» o «unidades gestoras» de una parte de lo que podríamos llamar «programas nacionales» (pensemos, por ejemplo, en materia de construcciones escolares, concentración parcelaria y ordenación rural, planes provinciales de colonización de grandes zonas, planes de expansión o desarrollo regional como el trasvase Tajo-Segura, etcétera) dará a las Administraciones locales nueva vida y la ocasión de participar y en muchas ocasiones decidir (no sólo ejecutar) muchas cuestiones que pueden serles encomendadas. Naturalmente que en estas tareas los entes locales no gozarán de esa teórica e incondicionada libertad de decisión que se postulaba en el viejo municipalismo para sus «asuntos privativos» (libertad, por otra parte, vacía de contenido como la realidad ha: demostrado), pero en cambio, en el marco o cuadro de directrices que el Estado señale, los entes locales con medios financieros. y servicios técnicos adecuados (los mismos del Estado: no hay

leyes» tan típico de la época, habría hoy que entender la inmensa y variada actividad programadora, procuradora y de gestión económica que reviste la Administración de nuestros días. También Fernández de Velasco aludía a la «doble personalidad de los organismos administrativos, según se les considere representantes: de una entidad o como delegados de otra, doble cualidad ésta que se revela en sus funciones según ellas sean o no realizadas en consecuencia de acuerdos ejecutivos desde luego, o no. En el primer caso son independientes del organismo total que constituye la Administración del Estado, se hallan desligadas de él; en el segundo son uno de sus rodajes》. (Fernández de Velasco, Recaredo, Resumen de Derecho administrativo y de Ciencia de la Administración, Murcia, 1920, pá. gina 313).

(47) Martín-Retortillo, S., «Planificación...», cit., pág. 100. Siguiendo la formulación hecha por García de ENTERría, E., en La Administración..., cit., páginas 110 y sigs. 
por qué duplicarlos) podrán participar razonadamente en la política, asociándoles al proceso de decisiones (48).

Esta es una segunda vía de potenciación de los entes locales.

Y tanto una como otra son el camino para una participación política real de los ciudadanos en las decisiones de gobierno. No en las grandes opciones, que seguirán correspondiendo al Parlamento y al Gobierno, sino en aquellas decisiones concretas y singulares que afectan directamente a su vida y a su entorno (49).

\section{UN EJEMPLO DE LO QUE NO HAY QUE HACER: EL TURISMO}

Tomemos un ejemplo, el sector del turismo, materia que resulta especialmente interesante, por varios motivos: primero, porque se trata de un fenómeno progresivamente creciente e importante desde muchos puntos de vista, que ha exigido en los

(48) Las múltiples ventajas que esta fórmula of rece, también para el Estado, y sobre todo para las propias tareas de gestión, en García de Enterría, E., La $\mathrm{Ad}$ ministración..., cit., págs. 112 a 114.

(49) No entro ahora en el análisis de las especiales características que reviste la participación en el sistema español a nivel parlamentario, cosa innecesaria en este momento. Baste decir que con carácter general se ha denunciado el hecho de que «la tradicional fórmula de participación del ciudadano en el poder político se muestra ya insuficiente» (Garrido Falla, «La participación popular en la Administración local», en Revista de Estudios dE LA Vida Local, núm. 154, julioagosto 1967, pág. 482). Por ello la nueva democracia se propugna hoy no sólo a nivel de los escaños parlamentarios-los grandes y radicales planteamientos-, sino en y desde la Administración, a nivel de las realidades concretas. Vid. lo que se dice más adelante, epígrafe 6. Y esta «participación» encuentra un campo de aplicación especialmente adecuado en la Administración local, como ha puesto de manifiesto Bopuera Oliver, J. M., «El sistema representativo municipal», en Problemas politicos de la Vida local, vol. V, Madrid, 1965; y del mismo autor, «La Provincia como cauce de representación politica», Revista DE Estudios DE LA VIDA Local, núm. 156, págs. 801 y sigs. Finalmente, un reciente y detallado análisis de la «Participación de los ciudadanos españoles en los asuntos públicos», con especial referencia al Régimen local, en Informe Nacional para la IULA (Union Internationale des Villes et Pouvoirs Locaux), preparado por los profesores Vallina Velarde y Gallego Anabitarte, Madrid, 1970. Recuérdese además, si se quiere, todas las clásicas y repetidas ventajas de los sistemas de gestión por los entes locales que vendrian a sumarse a ese valor central de la «participación política»: la inmediatez y conocimiento directo de los problemas, el sentido de responsabilidad de quien decide «asuntos propios», el control que siempre se realiza in situ mejor que desde el centro, etc. 
últimos años una intensa acción estatal, no sólo de ordenación: jurídica, sino, sobre todo, programadora, planificadora y gestora de actividades; segundo, porque es un típico campo de concurrencia e interferencia de competencias entre la Administración central y la local; y finalmente, porque disponemos en esta materia de una normativa que aborda frontalmente el tema de la competencia: la Ley de Centros y Zonas de interés turístico nacional. de 28 de diciembre de 1963 y especialmente la Ley de 8 de julio de 1963, sobre competencias en materia turística (50).

La situación que contemplan estas leyes, según se dice en el Preámbulo de la primera de ellas, es la de un país «con una afluencia de visitantes que llega hasta la saturación y el agobio en determinadas zonas», mientras otras «dotadas por la naturaleza de suficientes atractivos no están suficientemente desarrolladas, por la ausencia de una política de fomento que ordene, estimule o supla la iniciativa privada».

Ante esta situación la Ley se propone abrir los cauces jurídicos para la planificación y promoción de zonas y centros de interés turístico nacional, es decir, para la determinación de espacios y regiones del país que reúnan condiciones naturales: para ser objeto de tal calificación y reciban los beneficios que conlleva.

Pues bien, en esta tarea, tres caminos se ofrecían al Gobierno, según nos dice Fernández Alvarez, uno de los principales: autores del Proyecto de Ley de Zonas: «1) Legislar en particular, para cada zona, en función de iniciativas casi siempre privadas y de tipo aislado, respondiendo en general a necesidades e intereses puramente locales. 2) Estructurar un plan turístico general, dentro del cual se especificarán con toda claridad las.

(50) Esta disposición ha sido calificada por Villar Palasí de «insólita», calificación que no es peyorativa, sino elogiosa, pues «no es frecuente se dicten leyes. con la exclusiva y directa pretensión de regular competencias》 (VILlar PaLAsí, J. L., Aspectos juridico.administrativos del turismo, ponencia española presentada al I Congreso Italo-Español de profesores de Derecho administrativo, Sevilla, mayo 1966, edic. ciclostil, pág. 26. Cit. por José Fernández Alvarez, «El sistema de integración de normas y la Ley de Competencias en materia turística, de 8 de julio de 1963», en Problemas socioeconómicos y técnicos del desarrollo del turismo, Instituto de Estudios Turísticos, Madrid, 1967, págs. 285 y sigs.). 
zonas que en un determinado período habrían de gozar de protección por parte del Gobierno y en qué medida. 3) Determinar de antemano el techo o máximo de beneficios a conceder a las zonas turísticas, pero con amplia libertad por parte del Gobierno para ir decidiendo, tanto de oficio como a instancia de parte, los lugares a los que los mismos habían de alcanzar, así como su concreción definitiva» (subrayado mío) (51).

En cualquiera de estas formas o vías de actuación, pero especialmente en la tercera (que fue la elegida en definitiva), la decisión en cuanto a la determinación tanto de las zonas como de los centros en concreto queda reservada al Ministerio de Información o al Consejo de Ministros, a propuesta de aquél, según los casos (art. $4 .^{\circ}$ ) (52). A los entes locales o corporativos se les reconoce únicamente la posibilidad de «iniciar el procedimiento» para la declaración de centro o zona de interés turístico nacional (art. $7 .^{\circ}$ ) o de «elevar informes» al Ministerio para ilustrar la decisión de éste, que con los informes o consultas pertinentes de otros organismos competentes por razón de la materia, lo enviarán, si es necesario, a Consejo para aprobación por Decreto (arts. 12 y 13). En dicho Decreto se determinarán expresamente los beneficios que se concedan (art. 13). El sistema es el clásico centralista: la decisión queda reservada, en todos sus niveles y a todos sus efectos, a la Administración central (53).

(51) Fernández Alvarez, J., «La Ley de Centros y Zonas de interés turístico nacional», conferencia pronunciada en Tarragona, en Problemas técnicos, econó micos y juridicos de urbanización de zonas turísticas, I. E. T., Madrid, 1965, páginas 211 y sigs.

(52) La diferencia entre «Zonas» $y$ «Centros» es explicada así por los autores de la Ley: el concepto de Centro es «un concepto intermedio que sirva de puente para dar paso de una manera natural de terrenos sin protección a los enclavados en una Zona. Por esto es por lo que se exige en principio la existencia de dos - más Centros (art. 3.1 de la Ley) acogidos a los beneficios de la Ley, para poder declararse una «Zona» como de interés turístico nacional, sin perjuicio, natu. ralmente, de que se pueda excepcionalmente prescindir de esta circunstancia, cuando concurran razones especiales (art. 3.2 de la Ley). Es decir, que lo normal será la previa declaración de Centros y después de Zonas, pero sin que esto quiera decir que no pueda incluso darse el caso contrario, es decir, el de la declaración de Zonas en las que no haya-al menos, de momento-Centro alguno y en las que precisamente tal declaración pueda ser la causa de la ulterior declaración de Centros》. (Vid. Fernández Alvarez, J., ob. cit., pág. 230). Podemos decir, pues, que la Zona equivale a los «programas» y el Centro al «proyecto concreto».

(53) Una crítica de este sistema centralizador ha sido hecha por Montono 
Un enfoque descentralizador del problema, tal como hoy debe entenderse, supondría justamente una inversión del planteamien. to en la siguiente forma: a la Administración central corresponde evidentemente la estructuración de un Plan turístico general de promoción y creación de zonas y centros, que habrá de ser realizado sobre la base de unos estudios previos del incremento, tipo, periodicidad previsible, etc., del turismo, así como de las zonas o regiones más aptas por sus condiciones naturales o su equipamiento para su desarrollo y preferencia, a escala nacional. Estos planes o programas deben ser cuantificados al máximo, determinando, a ser posible, el número de proyectos concretos (esto es, el número de centros, en la terminología legal), así como sus características (número de alojamientos en hoteles, con sus diferentes clases, apartamentos, bungalows, camping, etcétera) y sus necesarias instalaciones mínimas de infraestructura (superficie, servicios mínimos, etc.). Sólo la Administración central puede llevar a cabo esta tarea.

Asimismo, es misión de los órganos centrales la determinación del sistema legal de beneficios y ayudas-es decir, el marco jurídico-bajo el cual se han de desarrollar tales actividades. Finalmente, debe cuantificarse igualmente, en función de los dos datos anteriores, el montante global de inversión o ayuda financiera que, por todos conceptos, correrá a cargo del Estado en la realización del Plan turístico general (54), y su división en programas regionales o zonales.

Una vez determinados estos programas regionales, correspondería a las instancias regionales, provinciales o locales-según se estime conveniente - la concreción o individualización de los lu-

Puerto en Revista de Estudios de la Vida Local, núm. 156, noviembrediciem. bre 1967, págs. 825 y sigs., especialmente 827.828 , y págs. $843-844$.

(54) Bien entendido que tal ayuda o cooperación financiera debe alcanzar no solamente al objeto estricto del proyecto de zona o centro, sino también a todos aquellos servicios generales que tienen los Municipios a su cargo y que se verán aumentados, encarecidos y necesitados de una adaptación o renovación como consecuencia de la declaración de un Centro o Zona. Por ello, en este cálculo o plani. ficación de la ayuda financiera hay que contar no sólo con lo que pudiéramos llamar los medios específicos (un hipotético «Crédito turístico»), sino sobre todo con la necesaria coordinación y vinculación de todas las fuentes financieras públicas generales que afecten a la zona (Banco de Crédito Local, Banco Hipotecario, Planes provinciales, etc.). 
gares que, en concreto, van a recibir la calificación de Centros o Zonas de interés turístico nacional, así como la gestión de tales programas, incluidas las facultades de concesión de los beneficios y ayudas previamente establecidos, a todos aquellos que se acojan al proyecto.

Sólo se descentraliza cuando se traspasan facultades de decisión (55). Y es en estas facultades (y no sólo en las medidas de preparación, estudio o consulta), en la medida de lo posible y hacedero, y sin merma de la unidad de la acción estatal, en las que hay que dar entrada a los ciudadanos. Naturalmente que ello exige de la Administración central una labor previa y difícil, de cálculo, de programación, de estudio, evitándose así, además, la improvisación y la arbitrariedad ministerial.

En resumen, se trata, como decía más arriba, de centrar la atención y poner el acento sobre los programas (no sobre los órganos o personas administrativas) bien definidos y cuantificados por la Administración central, y remitir a las instancias representativas locales la adopción de las decisiones concretas que, en el marco de aquéllos, deban adoptarse. A la Administración central corresponde la concesión y programación a nivel nacional; a la nueva Administración local (una Administración local representativa a nivel provincial o regional, según la materia o servicio de que se trate), la toma de las decisiones singulares.

Vistas así las cosas, por otro lado, resulta obvio que esta partición funcional-y no sectorial-de competencias supone siempre la atribución con carácter exclusivo, evitándose así los artificiosos y engañosos sistemas de competencias concurrentes, compartidas o indistintas, que son una fuente constante de intrusismo (56).

(55) Sobre las demás notas definitorias del concepto de descentralización, vid. mi estudio «Realidad y dogmática de la descentralización administrativa. Notas para la delimitación de un concepto», en Estudios homenaje al profesor López-Rodó, Madrid, 1970.

(56) Me refiero aquí sólo, naturalmente, a la relación Administración centralAdministración local, que es rigurosamente hablando el único caso de colisión opositiva de competencias al que bace referencia la descentralización, ya que lo que habitualmente se denominan competencias concurrentes entre distintos órganos de la Administración (por ejemplo, entre distintos Ministerios, con ocasión del turismo, a que se refiere el artículo $6 .^{9}$ de la Ley de 8 de julio de 1963), no suponen colisión alguna, sino que tienen un distinto objeto formal y son por tanto 
Resulta por todo ello criticable, a mi juicio (aunque explicable), el planteamiento de la Ley de competencias en materia turística que, respondiendo a la tendencia general, ignora las atribuciones contenidas en los artículos 101, 242 y 243 y atribuye con carácter exclusivo al Ministerio (artículo 2.ํ: será función privativa del expresado Ministerio) la ordenación, fomento y atracción del turismo que puedan realizar la Administración pública y los particulares (57).

\section{BREVE MIRADA AL TEMA REGIONAL}

Quizá no sea superfluo echar una mirada al tema regional, desde la perspectiva adoptada en este trabajo.

Dejando a un lado las significaciones históricas y las implicaciones políticas que han acompañado a la Región en los planteamientos nacionales de tiempos pasados, resulta hoy communis opinio entre nosotros (58), que la Región ha de ser entendida

plenamente compatibles: así la competencia del Ministerio de Trabajo para regular las condiciones laborales de los operarios de un hotel no excluye la del Ministerio de Información y Turismo para los aspectos propiamente hoteleros y turísticos. Por lo demás, dicha concurrencia no afecta para nada a la descentralización. (Confróntese Fernández Alvarez, J., ob. cit., pág. 295).

(57) El Tribunal Supremo, por otra parte, ha interpretado con estricto criterio, en favor del Ministerio, tal atribución de competencia (sentencia de 15-IV-1966, Aranzadi 1.836, Ponente: Excmo. señor don Dionisio Bombín): El Ayuntamiento de Benidorm impugnó el Decreto de 23.XII-1964, que desarrollaba preceptos contenidos en la Ley de 28-XII-1963 sobre Centros y Zonas de interés turistico nacional, solicitando se suprimieran de $\operatorname{los}$ artículos $12, c), 14-3, c), 15, c), 61 \cdot 1,69-2$ y 10-1, las palabras «licencias para obras y construcciones», por estimarlas opuestas al criterio mantenido por el legislador en el artículo 17-1 de la Ley desarrollada.

El Tribunal Supremo desestimó el recurso, afirmando que el legislador, dada la importancia de la actividad turistica, considerada hoy como la primera fuente de riqueza de la Nación, ha reservado al Ministerio de Información y Turismo la facultad de conceder las licencias $\mathrm{y}$ autorizaciones, sin perjuicio de que cuando estas obras o licencias no afecten al Plan nacional de Turismo, sigan siendo las Corporaciones locales las que, con arreglo a su legislación privativa (Ley de Régimen local), las concedan.

(58) Es, por lo demás, la conclusión a la que se ha llegado en toda Europa. Asi se han abierto paso en Francia las estructuras regionales. Y en la misma Italia, donde viejas motivaciones de antaño han operado inicialmente con gran fuerza en la estructuración de un Estado regional, parece que actualmente la motivación realmente operante es la optimalización de los servicios. (Vid. Gianns. N1, M. S., La región como unidad de acción administrativa, C y D, Escuela Nacional de Administración Pública, Madrid, 1970, págs. 29 y sigs.). 
como unidad de acción administrativa, fundamentalmente económica, y como espacio ideal para el montaje y prestación de algunos grandes servicios públicos.

Desde esta perspectiva económico-administrativa, varias posibilidades, sin embargo, se ofrecen al legislador en la configuración o constitución de tales unidades: en una primera opción, la creación de nuevas Entidades locales o la creación pura y simple de nuevas divisiones territoriales como meras circunscripciones administrativas del Estado; y dentro de esta segunda cabe a su vez una doble modalidad: bien la constitución de la Región como circunscripción administrativa de carácter general, esto es, como unidad de régimen común para el cumplimiento de los fines generales del Estado, bien la regionalización de servicios singulares, no sobre la base de una unidad común, sino sobre la base de circunscripciones especificas según la naturaleza y características de cada servicio.

De entre estas distintas opciones posibles, en cuyo detalle no podemos entrar ahora (59), las manifestaciones que han tenido lugar en los medios oficiales se inclinan claramente por la segunda. Así, el Consejo Nacional del Movimiento se pronunció en favor de la configuración de la Región como mera circunscripción territorial y no de carácter general, sino a efectos específicos (militares, docentes, turísticos, económicos, etc.) (60).

El profesor Jordana de Pozas (61), sin prejuzgar cuál sea el «tipo de Región» que se elija, se ha opuesto a la interpretación dada por el Consejo al artículo 45 de la Ley Orgánica deI Estado, según la cual cualquier otro planteamiento del tema re-

(59) Es, por lo demás, bien conocido el contenido de cada una ellas. Me remito, por todos, a los recientes estudios de Martín Mateo, R., El horizonte de la descentralización, I. E. A. L., 1969, págs. 194 a 199, y GuaIta, A., «La división territorial en la Ley Orgánica del Estado», Documentación Administrativa, número 125 , págs. 11 a 33 .

(60) El Dictamen del Consejo, a la vista del artículo 45 de la Ley Orgánica del Estado, afirmaba, como se sabe, la Provincia como unidad básica, que tiene carácter constitucional y que seguirá siendo la circunscripción administrativa de régimen común para el cumplimiento de los fines generales del Estado; y dejaba abierta la puerta a posibles asociaciones de entes locales (mancomunidades municipales o provinciales) para la consecución de fines específicos.

(61) «Las previsibles alteraciones...», en Revista de Estudios de LA VIDA Local, número 155,1967 , pág. 641 . 
gional vendría prohibido por esta Ley fundamental. Para él, ni la Ley Orgánica del Estado «ni ninguna otra de las Leyes Fundamentales contiene una prohibición de establecer otras categorías de entidades territoriales distintas del Municipio y de la Provincia» (62). Guaita, por su parte, opina que ciertamente la Ley Orgánica del Estado parece referirse en este artículo a «meras divisiones territoriales», pero que «en ningún momento prohibe la posibilidad de entidades regionales»; en una palabra - dice-, «respecto de este asunto la Ley Orgánica del Estado no ha supuesto ninguna innovación: es cuestión aplazada o de lege ferenda» (63). Al margen de otros testimonios doctrinales, más o menos extremos, podemos concluir que se ha producido un cierto acuerdo entre los autores sobre los siguientes puntos:

1) El mantenimiento de la Provincia como unidad básica de régimen común para los servicios generales del Estado, y como ente local de carácter superior que es preciso robustecer, potenciando, mediante una amplia descentralización, las competencias y medios de acción (técnicos y financieros) de las Diputaciones (64).

(62) Señala Jordana la deficiente redacción del artículo 45, que dice: «también podrán establecerse divisiones territoriales distintas de las Provincias»; si se hu. biera querido limitar el carácter de la Región a una mera división territorial, debiera haberse dicho «distintas de la provincial»; al no hacerlo así, y al aludir a «la Provincia» (ente local), «nada veda-concluye-que las unidades resultantes puedan tener el doble carácter que la Provincia tiene» (loc. cit.).

(63) Entiende, sin embargo, que «si las Provincias han de subsistir como entidades territoriales-y asi ha de ser, según la Ley Orgánica del Estado-, aparece al menos dudosa la conveniencia de personificar las Regiones» («La división territorial...», cit. pág. 29).

(64) Esta primera conclusión viene, por lo demás, impuesta por la Ley Orgánica del Estado. Fue propugnada en 1957 por García de EnTerría, que habló de «la provincialización del Régimen local español» (Problemas actuales del Régimen local, Sevilla, págs. 29 a 33). Lo que se produjo realmente en 1957 (Ley de Presupuestos) fue, como señaló NiETo, «la provincialización de los servicios públicos gestionados por el Estado» (o si se quiere de la acción estatal) como consecuencia de la metamorfosis sufrida, a partir de ese momento, por la Comisión provincial de Servicios Técnicos. (Vid. NieTo, A., Apuntes de Régimen local, 2." parte). Hoy parece que se vuelve de nuevo a la potenciación de la Provincia como ente local y nuestra doctrina se muestra decididamente conservadora de aquélla como «unidad básica general». (Así, López-Rodó, L., La Administración pública y las transformaciones socioeconómicas, Madrid, 1963, pág. 109; Carro, A., «La reforma de la Administración española a nivel territorial», en Problemas políticos de la Vida local, Madrid, 1965, vol. V, págs. 275 a 304, especialmente pág8. 300 y sigs.; Guarta, A. «El 
2) La configuración de la Región como una nueva circunscripción administrativa de carácter fundamentalmente socioeconómico (65) y más apta para la acción administrativa en ciertos sectores, algunos ya actualmente organizados sobre espacios supraprovinciales (Confederaciones hidrográficas, Regiones militares, Distritos universitarios, etc.). La doctrina ha propugnado la conveniencia de unificar las múltiples y variadas circunscripciones supraprovinciales existentes hoy día, que casi nunca coinciden en unas circunscripciones regionales generales, aunque, como ha señalado Guarta, hay que huir del espíritu geométrico «más quimérico que hacedero» y no siempre justificado en la realidad (66).

3) Se propugna igualmente la apertura de fórmulas asociativas de mancomunidad entre Provincias, hoy no permitidas en nuestra legislación local (67).

4) En cualquier caso, las Regiones no se conciben, hoy por hoy, entre nosotros como nuevas Entidades locales (personas jurídicas distintas del Estado), con autonomía, fines generales, propio ordenamiento, hacienda, etc. No se puede cerrar esta posibilidad hacia el futuro (y la Ley Orgánica del Estado la deja abierta), pero es razonable pensar que tal creación sería prematura y no exenta de riesgos. Es preferible-y nótese que éste fue el proceso histórico de las Provincias, inicialmente puras circunscripciones territoriales—que el tiempo dé unidad y cohesión

concepto de Provincia», en Problemas politicos..., vol. V, pág. 224, y más tarde en «La división territorial...», cit., págs. 15-18, etc.).

(65) Carro, A., «La reforma...», cit., págs. 300 y sigs. También, ampliamente, Meilán GiL, J. L., «Influencia de la planificación del desarrollo en la Administración pública», Documentación Administrativa, núm. 100, 1966, separata.

(66) Guaita, A., «El concepto de Provincia...», cit., págs. 227-228. Es claro sin embargo que cuando la Ley Orgánica del Estado habla de «nuevas divisiones territoriales distintas de las Provincias» no está pensando en divisiones especiales, sino generales, como el mismo autor apunta en «La división territorial en la Ley Orgánicas del Estado», cit., págs. 20.21. Se trata, pues, de crear «Regiones generales» (determinadas o acotadas por razones económicas), adaptando a ellas, en lo posible, las actuales divisiones especiales. En este sentido, Martín Mateo, R., El horizonte..., citado, págs. 194 y sigs.

(67) Vid. Alvarez-Gendín, S., «Organización administrativa de la Provincia», en La Provincia, Instituto de Ciencias Sociales, Barcelona, 1966, págs. 26 a $28 . \mathrm{Re}$ cientemente lo ha recordado MeILÁn, J. L., «Problemática actual...», conferencia citada. 
a las futuras Regiones, que se «rueden» las instituciones de gobierno y administración regional, que la población se habitúe a las nuevas unidades y a la nueva capitalidad de la Región, que las relaciones administrativas que surjan entre las distintas Provincias agrupadas en la circunscripción dé lugar poco a poco a relaciones económicas y a vinculaciones ciudadanas y hasta familiares entre las distintas poblaciones. Sólo entonces, una vez trabado este cañamazo de intereses, tareas y servicios comunes, creada esa «conciencia colectiva» (que debe, quizá, liberarse de nostalgias y prejuicios históricos hoy superados), podrá con fundamento pensarse en su creación como tales a través del Boletín Oficial del Estado.

Estas son, hasta el momento, las conclusiones a las que ha llegado la doctrina en su gran mayoría.

Evidentemente, de este planteamiento se desprende un riesgo: puesto que no hay nuevos entes locales, nuevas personas jurídicas distintas del Estado, las Regiones no van a ser instrumento adecuado de descentralización, sino al contrario, un medio de que sigan centralizadas algunas de las tareas que podrian ser encomendadas a las Provincias, y que, de existir aquéllas, serán planteadas a escala regional. El riesgo es evidente (68).

\section{DESCENTRALIZACION, REGIONALIZACION, PARTICIPACION}

En el fondo, la polémica sobre la naturaleza - central o localde los entes regionales responde a esta preocupación: ¿cómo la Región, mera circunscripción territorial, puede ser un instrumento de descentralización y no lo contrario? Aun aceptando que el concepto de descentralización se ajusta hoy entre nosotros a unos moldes dogmáticos que se basan sobre la distinta personalidad de los entes, conviene insistir en que su significado profundo y genuino es éste: el grado de participación de los ciudadanos en la toma de decisiones por el poder público (se entiende: por el poder gubernativo, dejando a un lado Legislación y Tri-

(68) Y ha sido visto por GuAita, A., «La división territorial...», cit., páginas 28-29. Y por Martín-Retortillo, S., «Planificación...», cit., pág. 103. 
bunales), participación que se realiza claramente en el ámbito local en tanto en cuanto los entes locales responden por naturaleza al principio de elección (69).

Ciertamente, si las Regiones se apoyan hoy sobre todo en una motivación optimalista de los servicios y de la acción económica del Estado (70), difícil será configurarlas como entes distintos con propia personalidad y, por tanto, difícil resultará conseguir en base a ellas «descentralización administrativa» en sentido clásico.

Ahora bien, si la descentralización se plantea desde la perspectiva del proceso de decisión, y si lo que se trata de conseguir con ella es la participación de los ciudadanos, cabe quizá plantear unas fórmulas intermedias de estructura regional que no sean nuevos entes, ni tampoco puros órganos estatales.

Se trata de instrumentar una auténtica participación ciudadana en los órganos de gobierno regional, con una representación en ellos de los entes locales y de los sectores económicosectoriales, y con la asignación de un sistema de competencias decisorias e insustituibles, en la gestión de los programas (vid. lo escrito supra). Se trata de instrumentar la participación en y desde la Administración (70 bis).

(69) Me remito en este punto a mi trabajo «Realidad y dogmática de la descentralización. Notas para la delimitación de un concepto», en Estudios homenaje al profesor López-Rodó, Madrid, 1970. El tema regional se plantea hoy-la afirmación es absolutamente general-como una via de realización de la democracia en un Estado en el que es cada vez más difícil al órgano tradicional de participación el Parlamento-intervenir de modo eficaz en la determinación de la política nacional y en su control. ( Vid. Martín Mateo, R., El horizonte..., cit., páginas 47 y sigs. («Administración y democracia»), y todas las referencias alli contenidas).

(70) Giannini, M. S., La región como unidad de acción..., cit., págs. 15, 16, 29 a 33, 37, 38. La idea regional-concluye-ha perdido hoy en gran parte sus motivaciones históricas (su papel tuitivo, democraticistico, defensor de los valores étnicos, culturales, etc.). Las raices de esa preponderancia de la motivación optimalista son fundamentalmente dos: el progreso tecnológico y la adopción de las técnicas de programación (loc. cit., págs. 29 y sigs.).

(70 bis) El sistema representativo de nuestro orden político, y las bases de «participación» del pueblo son los establecidos en los Principios del Movimiento Nacional (VIII) y en el Fuero de los Españoles (art. 10), que no sólo no vedan, sino que al contrario contemplan justamente un sistema de participación orgánica del «Municipio, Sindicato y demás entidades con representación orgánica que a este fin reconozcan las leyes» (entidades económico-sectoriales) en las estructuras de gobierno. Y nótese bien que nuestras Leyes Fundamentales no sólo prevén la «participación en las tareas legislativas», sino también «en las demás funciones de interés 
Vistas así las cosas, resulta hasta cierto punto indiferente que las nuevas unidades sean formalmente «entes personificados» (nuevos entes locales) o estructuras orgánicas del Estado (órganos «centrales»). Lo que resulta fundamental es que en tales unidades administrativas de programación y gestión (centrales. y locales) estén presentes los administrados afectados, y que lo estén con poderes de decisión libre e insustituible sobre determinadas materias y funciones. Lo cual se garantiza mediante la «elección» de la mayoría en los órganos deliberantes, la asignación de auténticas competencias exclusivas (funcionalmente) y la no existencia de sofocantes poderes de tutela (unos poderes de tutela y control deben existir, pero moderados y tasados) (71). Podría quizá objetarse que en esta formulación que aquí se

general» (Principio VIII) (Gobierno, Administración). Es, pues, perfectamente admisible en nuestro sistema constitucional-más aún: éste parece reclamarla-una participación de los ciudadanos en y desde la Administración, a nivel de las reali dades concretas.

(71) Desde esta perspectiva (el proceso de decisión) resultan quizá superfluas las polémicas sobre si determinados organismos son centrales o locales, y sobre si la transferencia a ellos de funciones o competencias administrativas son descentralización o desconcentración. Tal empeño responde al planteamiento tradicional (separación entre Administración central y local como dos ámbitos separados, con organizaciones distintas, con distinta personalidad). Desde otros puntos de vista resulta ilustrativo determinar si la Comisión provincial de Servicios Técnicos, por ejemplo, o el proyecto de Conseil régional francés, son órganos de la Administración central o local. Ahora bien, a los efectos de apreciar la descentralización que en ellos se opera, tal calificación no tiene mayor interés, y lo importante no es la pura calificación formal de estos órganos, sino determinar su composición y elección, sus facultades decisorias (incluido el carácter ejecutivo de sus decisiones) y la mayor o menor intensidad de la tutela (autorizaciones, aprobaciones, suspensiones, etcétera) sobre su actividad. Sobre la «Naturaleza juridica y encuadramiento orgánico de las Comisiones provinciales de Servicios Técnicos», vid. el trabajo de Mendizábal Allende, R., bajo ese título, en Revista de Administración Pública, número 41, 1963, págs. 71 y sig8. Señala MendizÁbal el interés práctico que tiene su calificación en un Ordenamiento jurídico como el nuestro en que muchos aspectos concretos (sustantivos y procesales) se regulan con distintas consecuencias según se trate de Administración central o local (sistema dualista general). Esto, que es cierto, no es un argumento en contra de mi afirmación, que se refiere únicamente a la posibilidad de «descentralizar» (léase «participar») a través de «unidades centrales». Aparte de que, como se ha destacado en muchas ocasiones, tal sistema dualista (dos Ordenamientos distintos y completos) no tiene hoy plena justificación en muchos campos, por lo que la doctrina ha reclamado repetidamente la conveniencia de homogeneizar los regímenes jurídicos en sectores como el procedimiento y recursos, contratos, función pública, etc.; distinto es el caso de los bienes y patrimonios donde hay peculiaridades históricas que, por responder a la realidad física y sociológica, deben ser respetadas. 
hace aparecen confundidas dos viejas categorías del Derecho clásico : la descentralización y la desconcentración. Debo decir que, en mi opinión, las dogmáticas diferencias entre una y otra técnica pierden gran parte de su radicalismo si el fenómeno se contempla a la luz de los sistemas de gestión a los que está llamada hoy la Administración moderna (gestión previsional, gestión por objetivos y programas, gestión integrada), en los cuales cada una de las unidades o escalones operacionales constituye un centro autónomo de decisión dotado de propia responsabilidad en el marco del programa aprobado; cada unidad actúa en base a una competencia objetiva e irrenunciable atribuida por el Ordenamiento, sin que desde este punto de vista funcional puedan apreciarse grandes diferencias por el hecho de su pertenencia o no a la misma persona jurídica (72).

Naturalmente, la diferencia entre una y otra técnica sigue siendo importante en la Administración actual, en tanto en cuanto los entes locales responden por naturaleza al principio de elección y en cambio los orgános periféricos del Estado son «designados», lo cual da a los primeros una mayor independencia y libertad de actuación. Pero justamente a lo que aquí se apunta es a una deseable «participación» (presencia representativa de los ciudadanos) en las estructuras orgánicas de la Administración central (lo cual es más difícil que en la local, pero no es impensable; de hecho, es una fórmula buscada hoy en todo el mundo) (73).

(72) Vid, en idéntico sentido, el trabajo de P. Germain, «Administration et méthodes modernes de gestion. Une introduction à des horizons nouveaux», en Administration, núm. 66, 1969, págs. 19 y sigs., especialmente página 25 . No puede olvidarse tampoco, como apunta Rivero, que aquella «conciencia colectiva» (comu. nidad natural, realidad sociológica y psicológica que el Municipio entrañaba) sobre la que se apoyaba la descentralización clásica se encuentra hoy muy disminuida («Problemas actuales de la Administración pública francesa», Documentación $A d$. ministrativa, núm. 100, págs. 114.115). Para una más amplia consideración del concepto y significado dogmático de la descentralización me remito a mi trabajo «Realidad y dogmática de la descentralización. Notas para la delimitación del con. cepto», en Estudios homenaje al profesor López-Rodó, Madrid, 1970.

(73) He puesto de manifiesto en mi trabajo «Administración institucional : origen y personalidad» cómo la descentralización por servicios surge originariamente con ese designio de instrumentar la participación a través del principio de representatividad social en los servicios. Y tenemos en nuestro Ordenamiento histórico un curioso precedente, que duró pocos años, de participación de los ciudadanos 


\section{CONCLUSION}

Este es, quizá, un planteamiento arriesgado, en el que se trata de hacer compatibles las exigencias de una Administración progresivamente tecnificada y despersonalizada, con el alto valor que la descentralización tiene en una sociedad políticamente sana. Sentido y valor que fueron señalados por nuestro gran Posada Herrera con precisión. Permítaseme, para terminar, la amplitud de la cita, que queda justificada en este caso por la tersura y belleza de su expresión, no menos que por la plena actualidad de su contenido: «Otra de las desventajas de la centralización es separar a muchas personas de los intereses de su localidad, o de su Provincia, y traerlos a ocuparse de los asuntos políticos. del país. Es imposible separar a muchos hombres de influir en el gobierno de su país, si no se les da una materia de que ocuparse. Es, pues, necesario para alimentar, para neutralizar esa multitud de ambiciones, que aquellos que no puedan aspirar a sentarse en los escaños del Congreso de los Diputados o del Senado para dirigir los intereses de la Nación puedan sentarse

en las estructuras orgánicas de la Administración central (se trata del Decreto de 16 de octubre de 1901, que creó la Dirección General de Navegación e Industria Marítimas, con un órgano de gobierno-la Junta-integrado también por representantes elegidos por los interesados en el sector); se pretendía con ello-escribe JordaNA, L., «Ensayo sobre las entidades públicas, representativas y profesionales en el Derecho administrativo español», en Estudios Jordana, I, pág. 233-《que el centro realizara su misión por los mismos administrados». Sobre las nuevas fórmulas posibles de «democratización» de la Administración central, vid. el sugestivo artículo de Rrvero, J., «A propos des metamorphoses de l'Administration d'au. jourd'hui», Mélanges Savatier, 1965, págs. 831 y sigs., con expresa referencia a la «participación» en las estructuras administrativas centrales. Ejemplos actuales de representatividad local y social en organismos calificados formalmente como organismos centrales son la Corporación administrativa Gran Valencia y Corporación administrativa Gran Bilbao (organismos autónomos dependientes del Ministerio de la Vivienda) y, aunque en escasísima medida (que debería ser ampliada), las Comisiones provinciales de Servicios Técnicos, actualmente órganos de la Administra. ción del Estado, en que «junto a los típicos miembros y funcionarios delegados de la Administración central, figuran los de las Entidades locales, Cámaras, Cajas de Ahorro, etc., y se deja abierta la posibilidad de incorporación de miembros de libre designación o de aquellas personas cuya colaboración se juzgue conveniente» (vid. Informe IULA, cit.). En otra línea de «participación» de los ciudadanos, pueden también recordarse las Juntas de Compensación en materia úrbanística, los Consorcios, nuestras viejas Comunidades de Regantes, etc.

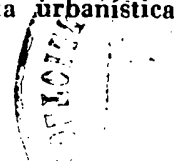


en los de la Diputación provincial para defender los intereses de su Provincia; si ni aun merecen esta honra, siéntense al menos en los del Ayuntamiento para cuidar de los intereses de su pueblo. Por este medio no sólo se alimentan una porción de ambiciones separándolas del punto a que se dirigirian, sino que se consigue también hacer que en el corazón de estos hombres nazca más afección a su patria y más amor a las instituciones. El hombre ama las instituciones que rigen en su pais cuanto mayor es la influencia que por ellas puede tener en su gobierno. Todos profesamos mucho afecto a la obra de nuestras manos y al gobierno de que formamos alguna, aunque pequeña, parte, pero, por el contrario, sería imposible querer hacer que hombres que sólo sirven en el país para pagar una contribución del fruto de su trabajo, puedan interesarse en sostener las instituciones que se han olvidado de ellos. Es, pues, necesario dar a los hombres influencia en los negocios públicos y extender el círculo de las personas que pueden influir en ellos, ya para satisfacer su ambición, ya para hacer que tengan amor a aquellas instituciones bajo las cuales viven» (74).

(74) Posada Herrera, J., Lecciones de Administración, Madrid, 1843, tomo I, página 37 . 